\title{
Aspectos sociales y espirituales de los sefardíes de Ragusa a través de la documentación testamentaria (siglos XVI-XVII)
}

\author{
Moisés ORFALI * \\ Bar-Ilan University
}

Tibi amico carissimo et magistro Ariel Toaff

Entre los protocolos notariales custodiados en las series Testamenta Notariae y Diversa Notariae del Archivo Histórico de Dubrovnik (Državni arhiv u Dubrovniku ${ }^{1}$ ) se conservan algunos testamentos de los miembros de la comunidad sefardí de Ragusa ${ }^{2}$ de los siglos

*moisesorfali@yahoo.com

1 A partir de ahora se nominará bajo las siglas DAD. Sobre los abundantes fondos recogidos en este archivo véanse J. TADIĆ, «Les Archives économiques de Raguse», Annales. Économies, Sociétés, Civilisations (Nov.-Dec. 1961) págs. 1168-1175; B. KreKić, Dubrovnik (Ragusa) et le Levant au Moyen Age (Paris 1961) págs. 161-165 («Note sur les Archives d'État de Raguse»); F. W. CARTER, Dubrovnik (Ragusa). A Classic City-state (London 1972) págs. 587-663; L. Lume, L'archivio storico di Dubrovnik. Con repertorio di documenti sulle relazioni della repubblica di Ragusa con le città marchigiane (Roma 1977).

2 Se trata de la actual Dubrovnik, situada en la costa este del Adriático en la zona meridional del litoral croata. La antigua Ragusa fue, en el año 615, el refugio de los habitantes de Epidaurus (a pocos kilómetros de distancia, hoy Cavtat) que huían del ataque de los pueblos del norte. Ragusa perteneció a Bizancio y a Venecia, fue ciudad libre y parte del Imperio Austro-Húngaro. Teniendo el Imperio Otomano anexados a los reinos de Serbia y de Bosnia, concedió a la ciudad el privilegio de erigirse en una pequeña república de comerciantes al estilo veneciano, con libre acceso a todos los mercados del Imperio Otomano, libertad retribuida con un pago anual de mil ducados de oro. Este acuerdo, que perduró hasta la disolución de Ragusa como ciudad-república en 1808, benefició a la pequeña comunidad sefardí local, que llegó a prosperar y desempeñar un papel comercial importante, controlando una buena parte del comercio entre Turquía y las ciudades de Venecia y Ancona. 
XVI-XVII ${ }^{3}$. La escasez de últimas voluntades judías comparada con los numerosos testamentos de cristianos que quedan en los mismos registros sorprende a los interesados en la temática. Precisamente por ello y por la importancia que tradicionalmente se ha dado a este tipo de documentos, me ha parecido interesante estudiar aquí estos testamentos, otorgados ante notarios cristianos, y además hacer referencia a otros documentos relevantes de la serie Diversa de Foris del mismo archivo.

Con este estudio no pretendo, en manera alguna, realizar un estudio económico de los sefardíes de Ragusa ${ }^{4}$. Sería absurdo pretenderlo a través de la simple y exclusiva utilización de las mencionadas series notariales, especialmente de un grupo tan determinado como el que constituyen los documentos de carácter testamentario dentro de la extensa tipología documental contenida en los protocolos. Generalmente, el principal rendimiento que se le puede sacar a este tipo de documentación, y que ha sido objeto de múltiples trabajos, ha estado dirigido al estudio de las «mentalidades», es decir, al conocimiento de la vida espiritual y de la actitud religiosa del individuo ${ }^{5}$, insertado éste

3 Entre ellos destacan el testamento de uno de los más eminentes poetas neo-latinos del Renacimiento, el médico judío Didaco Pirro (Didacus Pyrrhus Lusitanus o Flavius Eborensis, 1517-1599) y el testamento de Aarón Cohén de Ragusa (1590-1656), autor de la conocida obra Zecán Aharón (Venecia 1657). Véase DAD, Testamenta Notariae, LI, 27'-28' y LXV, 164'-166, y la traducción al serbo-croata de ambos textos por J. TADIć, Jevreji u Dubrovniku do polovine XVII stoljeća (Sarajevo 1937) págs. 307-308, 341-345.

4 Sobre el papel económico que desempeñaron los judíos en Ragusa véanse, $\mathrm{Z}$. Zlatar, «Export Trade of Balkan Jews via Dubrovnik in XVI and XVII Centuries», Zbornik Jevrejski Istorijski Muzej 4 (1979) págs. 107-110; B. KREKIć, «The Role of the Jews in Dubrovnik (Thirteenth-Sixteenth Centuries)», Viator 4 (1973) págs. 257-271; ID., «Gli Ebrei a Ragusa nel Cinquecento», G. Cozzı (ed.), Gli Ebrei a Venezia (secoli XIV-XVIII) (Milano 1987) págs. 835-844; I. BurĐELEZ, «Il ruolo degli Ebrei nel commercio marittimo di Ragusa e di Livorno», Studi Livornesi 3 (1988) págs. 63-67; IDEM, «The Role of Ragusan Jews in the History of Mediterranean Countries», Mediterranean Historical Review 6 (1991) págs. 190-197; Y. WIMMER, «Jewish Merchants in Ragusa as Intermediaries between East and West in the Sixteenth and Seventeenth Centuries», en M. Rosen (ed.), The Days of the Crescent. Chapters in the History of the Jews in the Ottoman Empire [en hebreo] (Tel Aviv 1996) págs. 73-150; M. Orfali, «Doña Gracia Mendes and the Ragusan Republic. The Successful Use of Economic Institutions in $16^{\text {th }}$-Century Commerce», en E. Horowitz-M. Orfali (eds.), The Mediterranean and the Jews. Society, Culture and Economy in Early Modern Times (Ramat-Gan 2002) págs. 175-202.

5 Veánse Ph. ARIÈs, L’homme devant la mort (Paris 1977); P. Chaunu, La mort à Paris, XVI-XVII siècle (Paris 1978); J. CoRIA Colino, «El testamento como fuente sobre mentalidades (s. XIII al XV)», Miscelánea Medieval Murciana 9 (1982) págs. 193-219; A. 
dentro de un grupo social o étnico determinado y, en suma, perteneciente a una sociedad en sus diferentes momentos históricos ${ }^{6}$. Creo, sin embargo, que a través de este tipo de documentación podemos analizar también aspectos socio-económicos de los sefardíes de Ragusa, aunque reconozco de antemano que resulta difícil aislarlos, puesto que los datos que al respecto nos proporcionan estos documentos están determinados por una actitud espiritual concreta que los impregna de forma concluyente.

Los seis testamentos que sirven de base a esta investigación están escritos en latín y en italiano ${ }^{7}$, idiomas que complican la lectura de los textos por razón de la construcción, léxico, abreviaturas peculiares, grafía, moneda y formas de pago, con predominio de los usos y costumbres

EIRAS RoEl et al., Aproximación a la investigación histórica através de la documentación notarial (Murcia 1985). Así como los artículos incluidos en «Les actes notariés: source de l'histoire social XVI-XIX siécles», en Actes du Colloque de Strasbourg 1979, y en «La Documentación Notarial y la Historia», en Actas del II Coloquio de Metodología Histórica Aplicada (Santiago de Compostela 1984); J. Casamitjana i Vilaseca, El Testamento en la Barcelona bajomedieval: La superación de la muerte patrimonial, social y espiritual (Pamplona 2004).

6 Entre los trabajos que versan sobre las sucesiones testadas por hispanohebreos se hallan: E. C. GirbaL, «Un testamento hebreo de la Edad Media», Revista de Gerona 5 (1881) págs. 382-386; L. Batlle i Prats, «Los judíos gerundenses en testamentarías medievales», Anales del Instituto de Estudios Gerundenses 4 (1949) págs. 250-253; J. Cabezudo Astraín, «Testamentos de judíos aragoneses», Sefarad 16 (1956) págs. 136-147; J. L. Lacave Riaño, «Un testamento hebraico fragmentario de Miranda de Ebro», Sefarad 46 (1986) págs. 271-279; E. Gutwirth, «Muerte y mentalidad hispano-judía (siglos XIII-XV)», El Olivo 13 (1989) págs. 169-185; M. A. Motis Dolader, «Disposiciones mortis causa de los judíos de Épila (Zaragoza) en el último tercio del siglo XV», Aragón en la Edad Media 8 (1989) págs. 475-498; A. Blasco MartíneZ, «Testamentos de mujeres judías aragonesas», Proceedings of the Tenth World Congress of Jewish Studies, B (Jerusalem 1990) págs. 127-134; IDEM, «Mujeres judías zaragozanas ante la muerte», Aragón en la Edad Media 10 (1991) págs. 77-120; E. MARín PADILLA, «Últimas voluntades judías: Testamentos de Duenya Falaquera, Reyna Abenardut y Davit Rodrich (siglo XV)», Anuario de Estudios Medievales 15 (1985) págs. 497-512; R. I. Burns, Jews in the Notarial Culture. Latinate Wills in Mediterranean Spain (Los Angeles 1996).

7 Las lenguas oficiales en la República de Ragusa fueron el latín (los protocolos de los Consejos se escribieron en latín hasta el año 1780) y el italiano (en la cual, entre otras, se mantuvo la correspondencia con los representantes oficiales y emisarios). Existieron tres cancillerías: una manejaba las ya mencionadas lenguas oficiales, otra el eslavónico, y otra el material en turco. 
locales ${ }^{8}$. En uno de ellos, se dice que «sigue el tenor de otra escritura, o sea, un folio escrito en español, que dice:...» ${ }^{9}$, fragmento que lamentablemente no he podido encontrar en el archivo. En otro, añaden los testigos del testamento y del codicilo ${ }^{10}$ que, además de haberse realizado conforme al sistema de costumbre de los hebreos, se escribió en lengua hebrea y fue interpretado por el ḥaḱam Perahiá Formón de la sinagoga de Ragusa y vertido al español por Aquila Pozza, escribano público y canónigo de Ragusa, a quienes los consejeros les facultaron para actuar cada uno por separado ${ }^{11}$. Parte de los testamentos son abiertos o nuncupativos ${ }^{12}$, es decir, han sido legitimados por testigos y realizados ante un notario cristiano que luego los consignará en su registro, y otros son cerrados. En cinco de los testamentos los testadores son hombres y en el sexto, una mujer, circunstancia que merece especial atención pues, salvo contadas excepciones, la mujer judía no suele ser protagonista del acto notarial; su comparecencia ante notario se realiza casi siempre de forma subsidiaria, junto al marido, el hijo

8 Agradezco la inestimable ayuda para superar toda clase de problemas paleográficos prestada por mi antiguo maestro y amigo el catedrático D. Ángel Riesco Terrero de la Universidad Complutense de Madrid y el Sr. D. Ivo Vecelić, archivero del Archivo Histórico de Dubrovnik (Državni arhiv u Dubrovniku). También agradezco a la prof. ${ }^{a}$ Ivana Burđelez, directora del Centro de Estudios Mediterráneos de la Universidad de Zagreb en Dubrovnik, su apoyo y estimulo para que este trabajo llegara a buen fin.

9 DAD, Testamenta Notariae, LXV, 164'-166: «Sigue il tenore di altra scrittura o sia foglio scritto in spagnolo, didelicet...».

10 Disposición adicional a un testamento, redactada por escrito, que modifica parcialmente lo dispuesto como última voluntad testamentaria sin posibilidad de institución o sustitución de heredero y tampoco de renovación ni desheredación. Véase A. Riesco Terrero, Vocabulario científico-técnico de Paleografía, Diplomática y Ciencias Afines (Madrid 2003) pág. 84.

11 DAD, Testamenta Notariae, LV, 22: «Additio nullo testimonio rumpi possit, quod quidem testamentum cum additione pro ut supra erat descriptum hebraicis caractere, et sermone, et interpretatum per Perachiam Formon Haham haebreorum Synagogae Ragusii sermone hispanico, et ex dicto sermone hispanico translatatum per signore Achillem Pozza, publicus et iuratus cancelarius Ragusii, ambos deputatos ad hoc per dictos dominos consules medio eorum iuramento respective».

12 Es decir, testamentos comunes abiertos, cuya peculiaridad no está en la escrituración material de la última voluntad del testador, sino en que éste manifieste de viva voz en presencia de las personas que autorizan el acto: notario y testigos, nombrando e instituyendo su heredero o herederos y, tal vez, también sus albaceas. Véase Riesco TerRero, Vocabulario científico-técnico, pág. 296. 
o el hermano ${ }^{13}$. En el caso aquí tratado, Ester que actúa por sí misma, se identifica como «mujer de Moisés Maestro, de grata memoria» ${ }^{14}$, ya que en el momento de redactar su última voluntad era viuda.

Para que el testamento sea válido son necesarias la capacidad jurídica (variable) y la capacidad de obrar (transtornos mentales, fuerza mayor, etc.). En cuanto a esto ultimo citaremos los siguientes ejemplos de nuestros testamentos: Benvenisti Nansí expone que, debiendo morir por razones obvias de justicia, hace este su ultimo testamento ${ }^{15}$; Isaías Cohén afirma que hallándose, por la gracia de Dios, sano y sincero de mente y en manera alguna indispuesto en cuanto al cuerpo, hace y ordena este su último testamento ${ }^{16}$. De José Esperiel nos dicen los testigos que lo encontraron enfermo postrado en su lecho y le rogaron respondiese sobre el sí, sí y sobre el no, no como los hombres sanos que están tranquilos y en su propio juicio y dijo que se estaba agravando y quería confesar sus pecados, encomendando su alma a Dios bendito y alabado, y testar su última voluntad; a continuación confesó y encomendó su alma a Dios y dijo que quería que el señor David Cohén, su cuñado, fuera testamentario con todas sus facultades ${ }^{17}$. Los mismos testigos aseguraron que algunos días después,

13 Además de los estudios mencionados más arriba en nota 6, resultan extremadamente interesantes el capítulo que dedica al tema de la mujer Burns, Jews in the Notarial Culture, págs. 100-117 y el estudio de C. Boccato, «Aspetti della Condizione Femminile nel Ghetto di Venezia (Secolo XVII): I Testamenti», Italia 10 (1993) págs. 105-135.

14 DAD, Testamenta Notariae, LVIII, 168: «Io Hester moglie del quondam Moise maestro bone memoriae...».

15 DAD, Diversa Notariae, XXVI, 114': «Io Senior Benvenisti Nansi dovendo morire per debito di giustitia faccio questo mio ultimo testamento...». En Responsa Ra ̌̌ daM, $H M$, n. $^{\circ} 350$ se cuestiona la validez del testamento de Samuel Benvenisti que fue redactado después de haber sido condenado a muerte por la justicia de la República de Ragusa, es decir bajo presión de una fuerza superior a su voluntad. Además, se trata de la legalidad notarial de un gobierno cuyas autoridades se renuevan constantemente cada año y por tanto ha de ser considerado inestable, amén de sus maldades.

16 DAD, Testamenta Notariae, LI, 27': «Trovandomi io Isai Coen dottore per la Dio gratia sano et sincero di mente nulla di meno indisposto del corpo, faccio et ordino questo mio ultimo testamento rievocando, cassando, et annullando ogni altro testamento et gionta di quello che per lo passato sin a questo giorno fatto havesti».

17 DAD, Testamenta Notariae, LV, 21: «... e lo ritrovammo infermo giacendo sopra il suo letto, e lo domandammo, e respose sopra il si, si, e sopra il no, no, come gli huomini sani, che stanno quieti nel loro giuditio, e disse egli sentiva gravarsi dalla sua infirmità e che voleva confessare i suoi peccati a Dio, raccommandando l'anima sua a Iddio 
volvieron a visitar a José Esperiel, que se hallaba en estado muy grave y, de nuevo, le volvieron a rogar que respondiese con verdad -diciendo sí o no- si se ratificaba en lo dicho en la primera visita y él respondió afirmativamente y añadió que... ${ }^{18}$. En otros casos, el testador se nos muestra enfermo, pero con la cabeza despejada. Así, Moisés Calderón afirma que, encontrándose enfermo de cuerpo, pero sano de entendimiento y de memoria para cuanto pudiere acaecer y en plenas facultades, hace y ordena este su ultimo testamento ${ }^{19}$; Ester Maestro manifiesta que encontrándose grave de alma en su extrema vejez y más aún, enferma de fiebre, pero absolutamente lúcida de mente por la gracia de Dios, sana y despejada de inteligencia, de intelecto y sabiduría... y queriendo para descargo de su conciencia y porque redundara en provecho de sus herederos, hace su último testamento y dispone en conformidad con lo que le dicta su buena conciencia ${ }^{20}$. Y Aarón Cohén, asimismo llamado Arón Isra Coén, alega que, hallándose yaciente en cama gravemente enfermo... y deseando no morir sin ordenar puntualmente sus cosas para descargo de su alma, no obstante haber hecho ya en dos folios que se incluirán en éste, su presente testamento, toda su última ordenación y voluntad testamentaria, al tenor de las cuales quiere y ordena ${ }^{21}$. Estos testamentos siguen en general las

Benedetto e Lodato, e tistare per respetto della morte, e disse la confessione, e raccommando l'anima sua al Benedetto e Laudato Iddio, e tistò, e disse, che vuole che'l signore David Coen suo cognato, che Dio guardi, sia epitropo sopra tutte le sue // facoltà».

18 Ibid.: «Item dopo di questo hoggi giorno di Marte di 23 del mese di Adar 5374 dalla creatione del mondo, noi altri firmati qui basso entrammo a visitare il detto Josef infermo della detta infermità col[lo]cato nel suo letto, et reposato in suo sentimento intieramente, et lo dimandammo, et lui rispose sopra il si, si e sopra il no, no, e tornò, e tistò per rispetto della morte, et affermò tutto lo detto di sopra, e disse di più che...».

19 DAD, Testamenta Notariae, XLIII, 182: «Io Moyse Chalderon, haebreo levantino, trovándomi infermo del corpo ma sano dell'intelletto, et di memoria per ogni caso che di me potesse avvenire et per ogni buon rispetto faccio et ordino questo mio ultimo testamento».

20 DAD, Testamenta Notariae, LVIII, 168: «Io Hester moglie del quondam Moise maestro bone memoriae ritrovandomi aggravata dagli anni, in estrema mia vechiaia, et anche inferma di feb[b]re, pure tuttavia, mediante la gratia del signor Iddio, sana, e sincera di mente, e dell'intelletto e sapendo che non é cosa piú certa a noi altri che la morte ne piú incerta del dí, e dell'hora sua, et volendo io per discárico della mia conscienza, e perché cosí cognosco che sia per concernere a miei posteri fare il mio ultimo testamento e disporre secondo che mi detta la mia buona conscienza».

${ }^{21}$ DAD, Testamenta Notariae, LV, 164': «Io Aron Coen, anzi Aron Isra Coen, trovandomi giacente in letto gravemente ammalato... et desiderando non morire senza or- 
mismas formalidades que los de los cristianos en Ragusa, lo que no tiene por qué extrañarnos, pues en uno y en otro caso el notario cristiano empleaba las mismas fórmulas. Como es lógico, no hacían la invocación cristiana a Jesucristo ni a la Virgen dejando ese requisito sin cubrir, excepto en el caso del testamento de Moisés Calderón en el que explícitamente se dice: «En el nombre de Cristo. Amén», y se data el testamento con referencia al año de la natividad ${ }^{22}$; esto último ocurre también en el testamento de Aarón Cohén ${ }^{23}$. Sin embargo, se observan algunas diferencias que conviene destacar. Por ejemplo, en el preámbulo de las últimas voluntades, algunas veces y seguramente por mimetismo, se incluyen alusiones a la brevedad de la vida y el desconocimiento de la hora de la muerte, pero no se manifiesta el miedo al más allá ni el deseo de conseguir la Gloria, tan frecuente en los documentos similares de cristianos. Así, Ester Maestro nos dice que hace su testamento «ya que no hay cosa más segura para nosotros que la muerte ni más incierta en cuanto a su día y hora» ${ }^{24}$; y Aarón Cohén confiesa que, no sabiendo la hora del transito de esta vida a la otra..., quiere y ordena que en todo y por todo se mantenga, atienda y observen sus últimas voluntades, suscritas por su propia mano, a las que en todo y por todo se refiere, y no ocurriéndosele decir otra cosa, alaba a $\operatorname{Dios}^{25}$.

Los cristianos concedían gran importancia a la elección del lugar de enterramiento y la cantidad de dinero que destinaban a ese menester solía ser elevada, pues muchos de ellos pretendían ser inhumados dentro de la iglesia, monasterios o en emplazamientos destacados. En cuanto al lugar

dinar per a punto le mie cose per la quiete dell'animo mio, però havendo io fatto in due fogli, che saranno qui inclusi in mio presente testamento tutta la mia ordinatione et ultima testamentaria volontà, al tenor di quali ordino et voglio che...».

${ }^{22}$ AD, Testamenta Notariae, XLIII, 182: «In Christi nomine Amen. Anno ab eiusdem Nativitate millessimo quingentesimo septuagesimo secundo, die XXIIII, Ianuarii Ragusii, in domo habitationis testatoris infraescripti...».

23 DAD, Testamenta Notariae, LV, 164': «L'anno della sua salutifera Natività 1656 , indictione nona, die vero nona mensis februarii, Ragusii domi solitae habitationis sitae in ghetto in Platea».

${ }^{24}$ DAD, Testamenta Notariae, LVIII, 168: «... sapendo che non é cosa piú certa a noi altri che la morte ne piú incerta del dí, e dell'hora sua...».

25 DAD, Testamenta Notariae, LV, 164': «... et non sapendo l'hora di mio transito da questa ad altra vita..., voglio che in tutto et per tutto si stia, attenda et osservi per essere mia ultima volontà, come dissi, et per essere sottoscritti di mia propria mano, et alli quali in tutto et per tutto mi riferisco, et non occorendomi dir altro, lode a Dio». 
de enterramiento de nuestros testatarios, todos eligen para sus restos mortales el cementerio judío de Ragusa (Žudioski Grebi), y sólo uno de ellos, Ester Maestro, ruega además con insistencia, siguiendo la última voluntad de su marido que pidió trasladar sus restos a Tierra Santa, ser enterrada a su lado y que echen cal viva sobre su cadáver para que, cuando exhumen los restos de él para llevarlos a Tierra Santa, lleven también los suyos y cumplan la manda ofrecida por ella ${ }^{26}$.

Al disponer su última voluntad, algunos manifiestan expresamente su deseo de revocar cualquier testamento o codicilo redactado con antelación; por ejemplo, Isaías Cohén en su testamento nos dice explícitamente que lo hace y ordena revocando o casando cualquier otro testamento y adición del mismo que él haya podido hacer... ${ }^{27}$. Además, declara que, no queriendo ser ejecutor el maestro Moisés, lo sea en su lugar Abrahán Abeatar ${ }^{28}$. Revoca el donativo de cien ducados, que legaba a doña Oro, hija de doña Clara Abensaquén (Abensahén), y le deja por el contrario un escrito de cincuenta ongari de oro $^{29}$, los cuales ha de recibir de Salomón Cabillo (Cabiglio),

26 DAD, Testamenta Notariae, LVIII, 168': «Prego instantemente anzi ordino e lo mando a tutti li presenti miei figli e figlie che sotto quell' obligo che tieneno, in virtú della legge del Signore, verso loro genitori debbano farmi sepellire ac[c]anto del sepolcro del mio carissimo consorte quondam signor Moise Maestro, presento et quando levaranno le sue ossa per farle portare nella Terra Santa, secondo che mi hanno promesso che insieme con le sue portino anche le mie, et dichiaro che ho ordinato a Samuel, uno delli presenti miei figli che al presente si trova solo qui meco, dopo la mia morte, mi debba sotterrare sopra della terra cavando il mio corpo fuori della cassa nella quale sará portato mettendo sotto e sopra del detto mio corpo di calcina viva acció che prima siano spolpate le mia ossa, et cavarle poi come di sopra ho detto a suo tempo».

27 DAD, Testamenta Notariae, LI, 27’: «... faccio et ordino questo mio ultimo testamento rievocando, cassando, et annullando ogni altro testamento et gionta di quello che per lo passato sin a questo giorno fatto havesti».

28 La documentación de archivo muestra que el comerciante de pieles Abrahán Abeatar actuó como árbitro en diversos litigios locales e internacionales (DAD, Diversa Notariae, CXXIX, 32'-34); estuvo involucrado en disputas personales (DAD, Consilium Rogatorum, LXXXIII, 186); se asoció en negocios con Moisés Cabillo (Kabiljo) (DAD, Diversa Notariae, CXXXVI, 35'-36) y figura como testigo en la ketubbá de Jacob Bendanón y Reina, hija del ya mencionado Moisés Maestro (DAD, Diversa de Foris, XXVII, 50-52).

29 Ongari (hongari, ungari o unghero), nombre italiano del ducado húngaro, extensamente utilizado durante el siglo XVII en el norte de Italia, por ejemplo en Módena, Parma y Tassarolo. El ongari presenta en el anverso a un santo guerrero (en las monedas 
además de las maderas para fabricar una nave, que están en el almacén del mencionado Cabillo ${ }^{30}$.

Finalmente, suele figurar una fórmula que viene a garantizar que la integridad del testamento no pueda quebrantarse ni romperse por testimonio de nadie como se nos dice en el testamento de Benvenisti Nansí ${ }^{31}$. En el testamento de Moisés Calderón, éste encomienda encarecidamente a su albacea la ejecución del mismo y que no pueda quebrantarse por ningún testimonio ${ }^{32}$. Isaías Cohén aclara que quiere que sus últimas voluntades no puedan ser revocadas por nadie ${ }^{33} \mathrm{y}$ José Esperiel nos dice que su testamento y la parte complementaria (codicilo), no pueden quebrantarse con ningún testimonio ${ }^{34}$.

Sintetizando las cláusulas y advirtiendo en notas lo más característico de las mismas, podemos remitirnos a nuestros puntos iniciales de referencia a partir de los cuales fundamentaremos nuestro estudio de los testamentos y nuestra posterior reflexión. Las cláusulas que nos permiten desvelar cómo concebían el acto de testar y qué virtualidad espiritual le otorgaba el testador sefardí ragusino de los siglos XVI-XVII son, evidentemente, los preámbulos espirituales.

\section{Testamento de Benvenisti Nansí}

El registro oficial del testamento privado de Benvenisti Nansí, fue realizado por mandato del señor Junio Miguel de Babalio (Iunii Michaelis

húngaras a San Ladislao), y en el reverso, la Virgen o un escudo. Su valor de canje era el de 24,10 liras venecianas o un zecchino. Véase E. Junge, World Coin Encyclopedia (New York 1984) pág. 263.

30 Ibid.

31 DAD, Diversa Notariae, XXVI, 115: «Hoc autem testamentum nullo testimonio rumpi posit».

${ }^{32}$ DAD, Testamenta Notariae, XLIII, 182’: «Et prego, che sia il sopradetto Gecutiel Finzi, hebreo, al quale raccomando la essecutione di questo mio testamento quod nullo testimonio rumpi possit, et cetera».

33 DAD, Testamenta Notariae, LI, 28': «Et voglio che questa mia volontá non si possa revocar in conto alcuno».

${ }^{34}$ DAD, Testamenta Notariae, LV, 22: «Additio nullo testimonio rumpi possit, quod quidem testamentum cum additione».

SEFARAD, vol. 66: 1, enero-junio 2006, págs. 143-182. ISSN 0037-0894 
de Babalio), miembro del Consejo Menor ${ }^{35}$, el 16 de febrero de 1571. En dicho registro se inserta el testamento que el señor Benvenisti había hecho en Ragusa el 17 de enero de 1571 ante los testigos Pablo de Tadeo (Paolo di Thadeo) y Biagio Vodopia, canciller.

El testador instituye heredero universal de sus bienes -una vez pagadas las deudas contraídas por él y cumplidos los distintos donativos y legados que se especifican- a su hermano (cuyo nombre omite) imponiéndole la obligación de desempeñar todas las ropas que él había empeñado en Venecia y, una vez rescatadas, venderlas y repartir su importe entre los pobres de Jerusalén ${ }^{36}$, añadiendo al valor de la venta 150 escudos.

Entre sus mandas y legados, figuran:

1) Una parte de sus mejores bienes más 200 ducados para dotes matrimoniales de dos jóvenes ${ }^{37}$, conforme al deseo de su querida madre;

35 Se trata del Consilium Minus que, junto al Consilium Maius y al Consilium Rogatorum, constituyen los tres consejos que trataban de la vida interna y de las relaciones internacionales de la República de Ragusa. El Consejo Menor estaba compuesto de siete senadores, además del rector. Su competencia era velar por el cumplimiento de las leyes y de las decisiones tomadas por el Consejo Mayor y el Senado. Véase F. M. Appendini, Notizie istorico critiche sulle antichità, storia e letteratura dei Ragusei (Ragusa 1802) pág. 187.

36 Los judíos de la diáspora, y entre ellos también los de Ragusa, consideraban muy importante asistir a los pobres de la Tierra de Israel en general y a los de Jerusalén en particular, para fortalecer su comunidad judía en peligro de extinción dada la situación de pobreza en que se encontraba. Véase al respecto G. NAHON, «Pour une approche des attitudes devant la mort au XVII siècle: sermonnaires et testateurs juifs portugais à Bayonne», Revue des Études Juives [=REJ] 136 (1977) págs. 47-48 y notas 208-210 y recientemente Y. Ben-NaeH, «Poverty, Paupers and Poor Relief in Ottoman Jewish Society», REJ 163 (2004) págs. 151-192.

37 Las dotación de novias pobres es un precepto tan importante, que se permitió incluso interrumpir el estudio de la Torá en público con el fin de cumplirlo. En la diáspora sefardí de Occidente las cofradías de dotar novias pobres y huérfanas tenía un marcado carácter socio-étnico, especialmente entre los descendientes de los conversos. Véase M. Bodian, Hebrews of the Portuguese Nation. Conversos and Community in Early Modern Amsterdam (Bloomington 1977) págs. 134-138; M. Orfali, «The Portuguese Dowry Society in Livorno and the Marrano Diaspora», Studia Rosenthaliana 35 (2001) págs. 143-156 y últimamente R. Levine Melammed, A Question of Identity. Iberian Conversos in Historical Perspective (Oxford-New York 2004) págs. 79, 119-120 y 130. 
2) a la Hevrá de Talmud Torá de Salónica ${ }^{38}, 50$ ducados cequines ${ }^{39}$;

3) al doctor de Ancona, que está en Ancona, 12 escudos;

4) a la sinagoga hebrea de Ragusa, deja para su enterramiento, 25 escudos así como 50 libras de aceite para sus exequias y para el preste de la sinagoga 5 escudos más;

5) a David Gallego deja por los servicios que le ha prestado 12 escudos $\mathrm{y}$, además de esto, que se le pague todo lo que diga que le ha prestado, aproximadamente seis escudos;

6) a su servidor José, 10 escudos y el correspondiente sueldo;

7) dinero suficiente para el rescate de Salamón de la galera hasta completar 25 escudos ${ }^{40}$;

38 Se refiere al «Talmud-Torá ha-Gadol» o Talmud-Torá central de Salónica, formado de la fusión de todas las instituciones educativas importantes de la zona tras la llegada de los expulsados de España. En él recibieron instrucción futuros eruditos talmúdicos que se contarían entre los mejores de la ciudad, así como cientos de otros niños. Su fama atrajo a alumnos de todo el Oriente Medio e incluso de centros asquenazíes de Europa oriental. El establecimiento se convirtió en el centro de la vida pública y judía, lugar que conservaría por espacio de cuatrocientos años. Su dirección estaba supervisada por ciertos notables de la comunidad de la ciudad que se encargaban asimismo de su mantenimiento. La institución recibía limosnas destinadas a sostener a los niños pobres, proporcionaba ayuda a los necesitados y tenía una imprenta que imprimía libros de rezos para los alumnos. En el Talmud-Torá de Salónica se formaron numerosas generaciones de dirigentes espirituales. Véanse entre otros Responsa Samuel de Medina, YD, n. ${ }^{\circ}$ 158, 167, 174; ibid., HM, n. ${ }^{\circ} 445$; A. S. AmARILLIO, «The great Talmud Torah of Salonica» (en hebreo), Sefunot 13 (1971-78) págs. 273-308; J. GELLER, «The Economic Basis of the Yeshivot in the Ottoman Empire» (en hebreo), East and Maghreb 1 (1974) págs. 167-221.

39 Zecchino, sinónimo del ducado de oro veneciano y algunas de sus imitaciones; su nombre deriva del italiano zecca (casa de la moneda). El zecchino junto al florín se convirtió en la moneda de oro más difundida como medio de canje en el período de transición de la Edad Media. Su valor permaneció estable hasta finales de la República de Venecia: 3,44 gramos de oro de 0,986 de pureza. En determinados lugares se le llamó sequin o cequin. Véase G. Boerio, Dizionario del dialetto veneziano (Venezia 1867) pág. 808; R. G. Dоту, The Macmilland Encyclopedic Dictionary of Numismatics (New York 1982) pág. 348.

40 Además del interés personal del testatario en la redención del cautivo, los sabios judíos y, basándose en ellos, Maimónides, decretaron: «La redención de cautivos precede a[l precepto de] mantener y vestir a los pobres. Y no hay [otro] precepto tan grande como el de redimir a los cautivos, porque el cautivo se encuentra entre los que pasan hambre y sed y están desnudos y corre peligro de muerte». Véase TB, Baba Batra 8b; Mišné Torá, Hiljot matanot 'aniyim, VIII, 10. Sobre la participación de los judíos de Ragusa en el res- 
8) a la madre del médico Abrahán, 3 brazales y medio de paño veneciano y a la mujer de Achar una pieza de mocaire de color;

9) a Samuel Bono ${ }^{41}$, una cadena de oro de 15 escudos para su mujer, por los servicios prestados;

10) dispone y deja que sea pagado de sus bienes todo aquello que debe en Ragusa;

11) a Abrahán (Abram) de Isaac Menahem ${ }^{42}, 500$ ducados por servicios de administración y otras prestaciones, cantidad que deberá incrementarse en 200 escudos más, correspondientes a la mitad de los bienes muebles de su casa, anulando dos recibos (de 1.885 ducados venecianos ${ }^{43}$ ) ya pagados;

12) a José (Josip) Salama, cuñado ${ }^{44}$ del médico Abrahán, 10 ducados por los servicios prestados;

13) a los pobres de Jerusalén, 150 escudos, y a los demás hombres de Ragusa, conforme al parecer de su heredero (su hermano), todas las ropas en levantina y soriana que se hallan en Venecia, que deberán venderse y cuyo valor se repartirá entre los pobres, pagando el rescate de dicho empeño.

14) a José (Josip) Saralvo, el joven, una vez anulado el escrito de deuda, la mitad de sus ropas de vestir y, finalmente;

cate de cautivos, véase M. ORfaLI, «Ragusa and the Ragusan Jews in the Effort to Ramson Captives», Mediterranean Historical Review 17 (2002) págs. 14-31.

${ }^{41}$ En los registros del archivo local Samuel Bono figura en una lista de judíos comerciantes dedicados todos ellos a la peletería y a realizar transacciones monetarias (DAD, Diversa Cancellariae, CLVII, 67-67'); involucrado en un litigio con otro judío de Ferrara sobre un envío de telas, recibió de indemnización 20 ducados por arbitraje de otro judío de Venecia, Moisés Cardiello (Mojsije Kardielo), (DAD, Diversa Notariae, CXVIII, 150').

${ }^{42}$ La única noticia que nos ofrece la documentación sobre Abrahán (Abram) Menahem es la de su participación con Menahem Amarillo (Amariljo) en la revisión de los libros de cuentas de José Yacar (Josip Jakar) que estaba en litigio con Daniel Rodrige (Danijel Rodrige) y la aduana turca. Véase DAD Diversa Notariae, CXVIII, 170-170'.

${ }^{43}$ El ducado veneciano fue una moneda de oro introducida por la República de Venecia en 1284, bajo el ducado del dogo Giovani Dandolo (1280-1289). Presentaba en el anverso al dogo de rodillas frente a San Marcos, santo patrón de Venecia, y en el reverso a Jesús. Su peso era de 3,5 gramos de oro de 0,986 de pureza. Véase Junge, World Coin Encyclopedia, pág. 279.

${ }^{44}$ Se trata del yerno del médico Abrahán y no del cuñado como erróneamente indica el notario (cf. DAD, Consilii Rogatorum, LXII, 212-212'; LXVI, 195). José Salama ejerció la medicina junto a su suegro, heredando su puesto con un incremento de salario (DAD, Consilii Rogatorum, LXXI, 156). El joven médico solía atender pacientes en Bosnia a petición de las autoridades turcas (el sancaḳbegi) y, en uno de esos viajes, falleció en Banja Luka. 
15) a su madre, las escrituras viejas y cosas personales que tiene depositadas en la sinagoga de Venecia, para que se las dé a la sinagoga que más le agrade.

\section{Testamento de Moisés Calderón}

La apertura y registro del testamento de Moisés Calderón, hebreo de Levante, se realizó el 30 de enero de 1572 en la notaría pública de Ragusa, ante los testigos Marino Francisco (Marinus Francesco) de Tudisio, juez, y Antonio Peregrino, notario. El testamento privado lo hizo en su propio domicilio, estando enfermo de cuerpo pero sano de mente, el 24 de enero de 1572 y en él:

1) instituye como albacea-ejecutor y gobernador de todos sus bienes en Ragusa, como en cualquier otra parte, a Yecutiel Finzi ${ }^{45}$, también hebreo del Levante, con plena libertad y potestad para rescatar todos sus créditos de cualquier persona, colegio o Universidad que sea que tiene contraídos al presente y puedan tener en lo sucesivo y pagar todas sus deudas a todos aquellos que consten como acreedores suyos, así como para defender todos sus derechos en cualquier juicio, ante cualquier juez, tribunal y autoridad del mundo y hacer y ejercitar ante la Corte todos los actos que fuesen necesarios para la recuperación de sus bienes.

2) nombra herederos de cuanto posee a sus hijos.

\section{Testamento de Isaías CohÉN}

Inscrito en la notaría pública de Ragusa el 17 de mayo de 1599 con la anuencia del juez Esteban Benessa y del notario Escipión (Scipio)

45 Yecutiel Finzi (Jekutiel Finci), procedente de Estambul residió en Ragusa durante los años 1570-1573. Figura en la lista de comerciantes judíos ragusinos hecha en el año 1572 (DAD, Diversa Cancellariae, CLVII, 67-67') y se le menciona con frecuencia como comerciante solvente y corresponsal entre comerciantes judíos de textiles del Imperio Otomano e Italia (DAD, Diversa Cancellariae, CLVI 193'; CLVII, 33', 83, 119, 145; CLVIII, 61', 125', 142; Diversa Notariae, CXVIII, 110, 218'; Consilii Rogatoraum, LXI, 24, 67). En el mes de junio del año 1572 Yecutiel Finzi se encargó de ciertas transacciones del difunto Moisés Calderón (DAD, Diversa Notariae, CXVIII, 45'-46) y en el mes de abril del año 1573 redimió cautivos judíos en Ragusa (DAD, Diversa Cancellariae, CLVIII 87'-88 y ORFALI, «Ragusa and Ragusan Jews», pág. 25). 
Lucaris, el testamento del doctor Isaías Cohén corresponde al que el testador había hecho en forma privada (ológrafo ${ }^{46}$ ) en su propia casa, sita en el barrio de Ragusa, donde viven los hebreos ${ }^{47}$, el 6 de noviembre de 1597. En dicho testamento, escrito de puño y letra por Isaías, Cohén, se incluía inventario de todos sus bienes con modificación de la redacción y última voluntad testamentaria establecida en otro anterior. Conforme a esta última voluntad:

1) designa como albacea-ejecutor de su testamento a Abrahán Abeatar ${ }^{48}$ en lugar de Moisés Maestro, nombrándole procurador-comisario universal; y

2) nombra a Gioia como principal heredera y usufructuaria, junto con sus hijas Tamara y Raquel (Rahel), de las cosas de su casa, del dinero contante existente y de un donativo de 200 ducados, con autorización para que el albacea-ejecutor nombrado pueda aumentar la cantidad y bienes asignados a Gioia hasta que se casen sus hijas y éstas puedan ser las herederas de su madre, una vez fallecida, sin que nadie pueda exigir cuentas a esta última; y dado el caso de que muriese cualquiera de las dos hijas, a saber Tamara o Raquel, antes de casarse, que se pase todo a la otra.

3) establece los siguientes legados o mandas: a) uno de 50 hongari de oro a Doña Oro, hija de Clara Abenzaquén; b) otro de 196 escudos en favor de Salomón Cabillo (Cabiglio); c) otro de 300 escudos para Aarón Amadio; y d) 63 talleri venecianos a favor de Marino Batitorre.

46 El término ológrafo se aplica no sólo al testamento común ológrafo, escrito de puño y letra por el propio testador o autor del acto de última voluntad, mediante el cual nombra heredero o herederos y, tal vez, albacea-testamentario, sino también a las firmas personales que garantizan la autoría del documento o texto documental o literario, a pesar de que el cuerpo escriturario lo haya trazado materialmente otra persona. Véase RIESCO Terrero, Vocabulario científico-técnico, pág. 300.

47 Se trata del gueto basado en la decisión del gobierno de Ragusa del 22 de abril del año 1540: Prima pars est de dando libertatem rectori et Consilio quod pro congregando Hebreos in unum habitandum possint eligere quinque aut sex domos pro sua habitatione et eo plus sicuti fuerit necessarium, et domos inventos referre debeant ad presens Consilium, et quod precipi faciant dictis Hebreis ut ferant signa quibus destinguantur a Christianis. DAD, Consilii Rogatorum, XLIV, 313'. Cf. disposiciones posteriores en XLIV, 178; XLVII, 249'-250'; XC, 67, 96-96'; LXXXIX, 134-134'.

48 Véase más arriba, nota 28. 


\section{Testamento de José EsPeriel}

Elevado a escritura pública por el sistema de registro oficial del testamento y del correspondiente añadido (codicilo) «nuncupativo», hecho de viva voz ante los testigos que abajo se citan, conforme a la costumbre hebrea, y correspondiente a José Esperiel (Josip Isperiel), hebreo (ya difunto); fue realizado en Ragusa el 13 de marzo de 1614 y presentado ante el señor presidente Miguel (Michaeli) Marini de Bona y los honorables jueces Juan Basilio y Luis Saraca, actuando como testigos presenciales, David Cohén, cuñado del testador, el ḥaḱam Peraḥiá Formón de la sinagoga ragusina, Moisés de Sansón Habillo (Habiglio), Rafael David de Abrahán Lanciano (Lančano), quienes, con la asistencia y asesoramiento de David Cohén, lo examinaron mancomunadamente y cada uno en particular, para darle validez, asegurando que dicho testamento era y correspondía al que hizo con plenas facultades y lucidez José Esperiel. A ruego de los mencionados testigos, se ordenó su registro oficial con el fin de que tanto el testamento como el codicilo adquiriesen validez a perpetuidad. Entre sus mandas y legados:

1) nombra a su cuñado, David Cohén, testamentario y principal albacea y ejecutor de su testamento y para ello le da plenas facultades de forma que pueda revisar sus libros de contabilidad y sus haberes y deudas para que así pueda cumplir y controlar con entera libertad y como guste cuanto él tenía dispuesto respecto de sus bienes;

2) ordena que casen a su hijo con la hija de su fiel amigo de idéntico nombre (José Esperiel);

3) dispone que su cuñado no dé a su hijo permiso para hacer uso de sus bienes, ni se los entregue hasta que no cumpla los 20 años, salvo que su

49 La documentación local menciona a Aarón Amadio (Aron Damadio) en transacciones monetarias de comerciantes entre Ragusa y Ancona, véase Diversa Notariae, CXXX, 14-14'. También figura de testigo en la ketubbá de Jabob Bendanón y Reina, hija de Moisés Maestro (14 de tišré 5363 [1603]), véase TADIć, Jevreji u Dubrovniku, pág. 172.

50 El tallero (talleri) veneciano aparece a finales del siglo XVI entre las monedas que circulaban en Mantua, Messerano y Florencia. El Ducado de Saboya y la República de Ragusa lo adoptaron en diferentes períodos; su difusión fue muy extensa por el Levante desde mediados hasta finales del siglo XVIII. Sin embargo, nunca logró competir como moneda principal de canje entre los diversos estados y ciudades italianas con el escudo. Véase Junge, World Coin Encyclopedia, pág. 245. 
cuñado -nombrado ejecutor principal de dicho testamento- crea oportuno darle con antelación su conformidad.

Todo ello afirmaron los testigos haberlo oído de boca del difunto José Esperiel que les encargó que lo escribieran y firmaran en Ragusa, el mencionado 23 del mes de Adar; lo firmaron el testador y los testigos Perahiá Formón y Rafael David de Abrahán Lanciano ${ }^{51}$. Además, añadieron que dicho testamento y codicilo, realizado conforme al sistema y costumbre de los hebreos, se escribió en lengua hebrea y fue redactado por el hak $a m$ Perahiá Formón, de la sinagoga de Ragusa, y traducido al español por Aquila Pozza, escribano público y canónigo de Ragusa, a quienes los consejeros les facultaron para actuar cada uno por separado.

\section{Testamento de Ester, mujer de Moisés Maestro}

Abierto y elevado a escritura pública el testamento cerrado de Ester, mujer de Moisés Maestro ${ }^{52}$, fue entregado en la notaría pública de Ragusa el 23 de noviembre de 1628, para su registro y validez perpetua y ratificado por los testigos Jerónimo Menza y Aquila Pozza. Sus últimas voluntades las dispone la testadora de la siguiente manera:

1) nombra herederos, a partes iguales, de sus bienes muebles e inmuebles a sus queridos y amados hijos: David, Salomón, Jacob, José, Samuel, Isaac y a su hija Reina, a quienes personalmente ya se los había entregado excepto las cosas de uso personal y un pequeño ajuar que lega a su hija Reina, viuda de Jacob Danón;

2) ordena a todos sus hijos y, en especial, a Samuel, que la entierren directamente en el suelo, sin ataúd, al lado de su marido Moisés Maestro y que echen cal viva sobre su cuerpo, para que cuando exhumen los restos de él

${ }^{51}$ Los firmantes testifican que la muerte de José Esperiel tuvo lugar el 25 del mes de adar, año de la creación de 5374, firmando este testamento los testigos en Ragusa el primer mes de nisán de 5374; dichos testigos son Perahiá Formón, Moisés de Sansón Habillo, Rafael David Lanciano y David Miranda.

${ }^{52}$ De Moisés Maestro he podido averiguar sólo que avaló a los judíos de Ragusa: Jacob (Jakov), José (Josip) y Sadik Bendanón, en su deuda de 459 ducados a los hermanos Gučetić, y, al estar su hija Reina casada con Jacob Bendanón, condonó esta deuda considerándola como parte de la dote de su hija. Véase DAD, Diversa Notariae, CXXXIV, 24'-25. 
para llevarlos a Tierra Santa ${ }^{53}$, lleven también los suyos y cumplan la manda ofrecida por él.

\section{Testamento de Aarón Cohén}

El testamento (cerrado) de Arón Isra Haebrei, entregado para su guarda, conservación y elevación a escritura pública en la notaría de Ragusa se extrajo, abrió, leyó y publicó en el año 1656 por los señores cónsules en orden a su registro y perpetua validez, actuando como juez el Sr. Vuladissavo de Luca y de Goze, y como testigo y ayudante Florius de Staijs. Es interesante que la copia de dicho documento hace referencia al tiempo, el año 1656 de la Navidad, indicción 9. a , el 9 de febrero en Ragusa, y al lugar, dentro de la casa habitación sita en el gueto de la calle Lojarska (actualmente Žudioska), hallándose postrado en cama y muy enfermo, pero consciente y con deseo de ordenar todas sus cosas, para tranquilidad de su espíritu, antes de morir. El testador quiso que su primitivo testamento, escrito en dos folios, se incluyera en el que nuevamente hacía, como expresión de su última voluntad que además quería suscribir con su propia mano.

El texto de los dos folios insertos en dicho testamento, escritos uno en español y el otro en hebreo, vistos y examinados en profundidad por varias personas $\mathrm{y}$, sobre todo, por los doctos y peritos hebreos Salomón Cagli y Abrahán Abeatar, fueron traducidos al italiano para su mejor comprensión, sin que entre uno y otro (texto) se observara

53 Todos los patriarcas tuvieron en alta estima el entierro en la Tierra de Israel porque la Tierra de Israel recibe el nombre de «Tierra de vida» (Ezequiel 26, 20), y «tierras de la vida» (Salmos 116, 9). Los muertos de la Tierra de Israel vivirán los primeros en los días del Mesías (TJ, Kil'ayim, cap. 10, 4; GenR, pericopia Șaw). E incluso Jeroboam hijo de Nabat y sus compañeros vivirán hasta los días del Mesías, y ¿qué es lo que hizo que se libraran de ser condenados al guehenom y vivieran? su sepultura en la Tierra de Israel, tal como está escrito: «y su tierra expiará [los pecados de] su Pueblo» (TJ Ketubbot, 12, 3; PesR, primera parte). Había quienes tenían por costumbre poner polvo de la Tierra de Israel sobre el cadáver de la persona muerta en la diáspora, y se le consideraba como si hubiera recibido sepultura en la Tierra de Israel (Midraš Talpiyot). Y la sepultura en la Tierra de Israel tiene un nivel tal de santidad, que se permitió sacar al muerto de su sepultura en la diáspora para enterrarlo en la Tierra de Israel (Šulján 'Aruj, YD, 363); esa es, justamente, la voluntad del marido de la fallecida y de ella misma, según expresa en su testamento. 
discrepancia alguna; se registraron por mandato de los mencionados cónsules.

El tenor del primer folio, escrito en caracteres hebreos, es como sigue:

Comienza con la invocación del nombre de Dios, al que acude pidiéndole ayuda tanto para él como para sus hijos David, Aarón y Ester, porque en Dios ha confiado su corazón, conforme a un salmo de confianza y ardiente súplica ${ }^{54}$, le pide que por Su piedad y misericordia, mande a sus sucesores tras él, que guarden Sus caminos para hacer limosna ${ }^{55}$ :

1) a David, que se guarde de no olvidar las mišnayiot, que sabe de memoria;

2) a Aarón, que es versado en la Mišná y en la Guemará, le pide que se dedique a su estudio un poco del día y un poco de la noche con su querido yerno, con Rafael Cohén y con Manuel, con quienes compartirá la lectura de la Ley y Dios los ayudará y velará por ellos;

3) a su hija Ester le deja como herencia 100 ducados y, también, el pequeño séfer [Torá] con sus ornamentos que, después, pasará obligatoriamente a sus herederos sin poderlo donar a otras personas, ni tampoco vender o empeñar; si quisiera darlo a su hijo Abrahán, le da licencia pero con las condiciones anteriormente dichas;

4) para David y Aarón los otros dos sefarim con sus ornamentos, con idéntico impedimento de venderlos, empeñarlos o regalarlos;

5) nombra curador-albacea y ejecutores a su yerno José Baruj (Josip Baruh) y a su sobrino Rafael Cohén y a otros sobrinos: David y Aarón Franchi (Franco);

6) declara que quiere estampar (publicar) con el nombre de Dios el libro de su abuelo, de bendita memoria, y el suyo, que ya ha hecho y revisado. Y el de su abuelo, cuando esté enteramente copiado, se vaya revisando y después se titule el libro de su abuelo Šemen ha-Tob y leccionario del Génesis, y el suyo, Zecán Aharón, y leccionario del

\footnotetext{
54 Salmo 28, 6-7.

55 Aarón Cohén trata de marcar el camino a seguir, una actitud a imitar para con los necesitados. La limosna no se considera aquí como camino de salvación (cf. Prov. 10, 2) o una vía expiatoria, sino más bien como expresión de la caridad o amor de Dios; por lo tanto, quien ama a Dios debe evidentemente socorrer al pobre.
} 
Génesis y lo mismo de Nebiim, Ketubim y Maamarim, procurando que la impresión sea clara ${ }^{56}$;

7) que se impriman ochocientos ejemplares, de los cuales doscientos se enviarán a Constantinopla, cien a Salónica, cincuenta se repartirán en Venecia, veinte en Sofía, diez en Ancona, veinte en Roma, cincuenta en tierras tudescas (alemanas), cincuenta en lugares de Amsterdam, cien repartidos en distintos lugares de Italia y Jerusalén y algunos en particular para quienes los pidan;

8) se darán gratuitamente los de Jerusalén y el resto se venderá a precio de coste. El dinero que se recaude se dará al señor Samuel Abuaf y a sus hermanos, para mantenimiento de su lugar de estudio en Jerusalén, con ellos o aparte, como les plazca;

9) del resto de sus cosas y del negocio de la venta de sus libros, que durará por espacio de cinco años y se procurará sea ventajoso, se restará la décima parte (el diezmo) del valor total que se empleará para casar huérfanas ${ }^{57}$; de este $10 \%$ también treinta ducados a cada uno de sus parientes y, en particular, a los nietos de su tía Estrella (Streglia) y, si no fuera suficiente, se complementarán con las ganancias recaudadas;

10) la tienda seguirá en activo durante cinco años dirigida por Jacob de la misma manera que se ha estado haciendo hasta ahora y en ella se llevará la contabilidad dando cuenta en ducados de las recaudaciones en Venecia, Ancona y Turquía; sobre lo que se obtuviere de ganancia le dará a Jacob un tercio como hasta ahora;

${ }^{56}$ Su títulocompleto ̌̌emen ha-Tob 'al ha-roš ̌̌e-yored 'al ha-zacán, zecán ha-Aharón [del Sal 133, 2: «Es cual óleo exquisito sobre la cabeza, que desciende por la barba, la barba de Aarón»] (Venezia 1657).

57 El precepto de brindar ayuda pecuniaria a la doncella que quiere contraer matrimonio adopta distintos aspectos en la tradición judía que varían con el tiempo y el lugar. En la época de los Sabios se ponía el acento justamente en la ayuda a las huérfanas y no en general a las hijas de los pobres que carecían de medios para dotarlas; esto es lo que se propone hacer en este caso el autor del testamento. Véase Mišná, Ketubbot 6, 5; TB Ketubbot 67a; TJ Ketubbot 6, 5 (30d). La Tosefta prosigue esa misma línea de pensamiento: «[Si] un huérfano y una huérfana quieren contraer matrimonio, se asiste en primer lugar a la huérfana y después al huérfano porque el oprobio de la mujer es mayor que el del hombre» (Tosefta, Ketubbot 6, 5, ed. Liberman, New York 1966, pág. 77). Según Liberman, lo que esto significa es que el oprobio de una mujer sin marido es mayor que el de un hombre sin esposa (Tosefta ki-feshuțá, 6, New York 1966, pág. 282). Una interpretación distinta en Oṣar ha-geonim, Ketubbot, 2, ed. Levin (Jerusalem 1939) pág. 39. 
11) a su madre, que reside y residirá con él en la casa, se le dará de salario veinticinco ducados al año y también una saya de brocado blanco;

12) el zupón de velo a dos colores se entregará a su hermana con facultad de dárselo a sus hijas. El resto de las ganancias acumuladas, siempre en relación con el diezmo, se repartirá en seis partes, una parte para Rafael y la parte restante del capital para sus sobrinos: David y Aarón Franco y un tercio para Abrahán Baruf y sus hermanas a partes iguales con tal de que el primero cuide de su padre mientras esté soltero;

13) recomienda a todos que se traten con verdadero amor y no haya entre ellos discordia por su decisión;

14) encarga a David y Aarón y a sus hijos, que durante estos 5 años y aún después, para siempre, envíen al Talmud Torá de Safed y al Talmud Torá de Jerusalén ${ }^{58}$, lo que él acostumbraba a mandar anualmente de su cuenta y de la de su padre, como consta en los libros; también seguirán enviando lo que él, por delegación, mandaba a cuenta del hebreo Abrahán Molḥo (Molxo) y David Benzaquén (Bensaxen), conforme a lo establecido en el libro;

15) encarga a David y Aarón mandar lo que él solía dar cada año a Abrahán Molḥo y a David Benzaquén que han vivido a sus expensas según consta en el libro. Para mayor seguridad, él ha dejado en las cajas de Venecia sus libros pero que, de momento, se sirvan de lo establecido en el libro de su padre en el que se hace referencia a Molḥo y Benzaquén;

16) estarán siempre obligados en lo que tengan que enviar para Tierra Santa, repartiendo el dinero según lo registrado en los libros y las notas.

El testamento sigue el tenor de un folio escrito en castellano que revela la rectitud de un hombre que desea pasar a mejor vida sin quedar en deuda con nadie, además de seguir manteniendo a quienes dependieron de él:

17) al señor Paolo di Menze le debe sus cambios y el seguro, cuya nota consta por escrito en su libro. Tiene a su nombre lo que está en poder de Niccolo Bona, que ha dado al Magiair, y los rasos de los Inviti y de los Cachi;

58 El número de estudiosos de la Torá en las academias rabínicas de Jerusalén era reducido en comparación con Safed, debido a las difíciles condiciones que reinaban en dicha ciudad. Sobre la escasez de provisiones y dinero, y los medios de recaudación para mantener las academias rabínicas, véase GelLER, «The Economic Basis of the Yeshivot», págs. 172-177 y 180-221. 
18) al señor David Ohev (Oef) cien escudos, a cuenta de los cuales se le han dado, por mediación de Raffaele, diez escudos.

19) en lo que respecta a [José] Saralvo la cuenta está escrita en el libro. Manuel está enterado de todo y de todas las cuentas que hay en el libro por si hubiera que aclarar cualquier cosa. Dicho Manuel debe un escrito de aproximadamente cien ducados; que se le condonen ya que ha copiado y copia los libros. Además de esto, se le pagará su salario a partir de ahora, restando lo que debe en el libro aparte de lo aquí consignado;

20) que alguien se cuide de cancelar los libros de costura [?] y todo cuanto sea necesario.

El gran respeto que tenían las autoridades a Aarón Cohén por su calidad humana se refleja en el trato que recibió durante el período en que estuvo detenido por el caso Yešurún. No fue maltratado, como era corriente en la época, sino que lo liberaron poco tiempo después y se quedó por el resto de su vida en la ciudad que lo vio nacer. Aarón Cohén también puso por escrito, minuciosa y reiteradamente, el caso Yešurún que convulsionó a toda la comunidad. A sus comentarios y homilías sobre la Biblia y el Talmud en la obra Zecán Aharón, añadió, con el título de Ma'asé Yešurún, la narración de la calumnia de crimen ritual del año 1622 y del juicio que se llevó a cabo por este motivo, en el que se condenó a Isaac Yešurún al calabozo ${ }^{59}$. Se trata de un testimonio fiel de la última calumnia de este tipo en Ragusa, que coincide con los datos de los protocolos depositados en el archivo local ${ }^{60}$. Para conmemorar la liberación de Yešurún, compuso Aarón Cohén un himno de acción de gracias llamado 'En ke-'El Yešurún ${ }^{61}$ («Ninguno hay como el Dios de

59 Véase I. A. Kaznačı́c, Processo di Isach Jesurun, israelita di Ragusa, nel 1622 (Dubrovnik 1882); T. MoRTiDIDJJA, «Antisemitizam u Dubrovniku god. 1622», Vjenac 15 (1883) págs. 9-12; E. LeVI, «Proces Jichaka Jesurun u Dubrovniku», Jevrejski glas 5 (1935) págs. 41-45; TAdić, Jevreji u Dubrovniku, págs. 119-134; M. PeranI, «Un’accusa di omicidio rituale contro gli ebrei di Ragusa-Dubrovnik nel 1622: Il Ma'aseh Yeshurun di Aaron ben David ha-Kohen, Venezia 1657», Annali di storia dell'esegesi 16 (1999) págs. 403-434.

60 DAD, Consilii Maius, XXXIV, 200’-201

${ }^{61}$ Yešurún, título honorífico (yašar, 'recto') dado a Israel en la Biblia. El himno se inicia por tanto con la declaración: «Ninguno hay como el Dios de Israel». Recordemos aquí que la elegía que describe la persecución de la aljama de Toledo en el año 1391 se llama 'Adat Yešurún, comienza: «Todos vosotros sois asamblea de Yešurún». Véase C. Rотн, «A Hebrew Elegy on the Martyrs of Toledo, 1391», JQR 39 (1948) págs. 123-150. 
Yešurún», Dt. 33, 26) y en sus versos incluyó también datos relacionados con el proceso. Las generaciones posteriores recitaron este himno en la sinagoga de Dubrovnik, después de la lectura de la pericopia de Wa-yehí [Gn 47, (28-31); 48-50] que finaliza el primer libro de la Biblia: el bien triunfa del mal. José ha perdonado a sus hermanos, hay consuelo y no castigo. Reina la paz, sobre todo en los corazones.

Hemos visto que nuestros testadores, amparándose en el principio de la «ley del reino es la ley [para nosotros]» (diná de-maljutá diná ${ }^{62}$ ), ordenaron sus últimas voluntades ante notarios cristianos al igual que otros correligionarios suyos en otras comunidades de la diáspora judía ${ }^{63}$, lo que ofrecía plenas garantías a los causantes, no tanto por los testigos cuanto por el fedatario público cristiano. Esto se puede deducir claramente de documentos como el legado y mandas de Moisés Cavalero a favor de su madre y hermano tras el terremoto que afectó a Ragusa en el año $1667^{64}$, o el cobro de documentos legales de difuntos hebreos ragusinos ${ }^{65}$.

${ }^{62}$ Guittín 10b; Nedarim 28a; Baba Qama 113a; Baba Batra 54b-55a.

63 Sobre la serie de condiciones que el derecho privado hebreo, llamémosle por su nombre halajá, establece en la aplicación de la «ley del reino», véase M. ORfaLI, «La "ley del reino" y las aljamas hispanohebreas», en El legado de los judíos al Occidente europeo. De los reinos hispánicos a la monarquía española. Cuartos encuentros judaicos de Tudela (Tudela, 11-13 de septiembre de 2000) (Pamplona 2002) págs. 147 ss.

64 DAD, Diversa de Foris, CXX, 14'-15: «Die 6 Nov. 1685. Moise Cavalero ebreus sponte etc. accedens in Canceleriam presenti pub[li]co instrum[en]to debita haereditate Paterna, et bonis fraternae Societatis omnimodam plenariamque potestatem, debit, cessit et renunciavit, prout dat cedit et renunciavit Rennae eius matri, et Samueli Cavalero eius fratri, ad habendum tenendum gaudendum, utendum, fruendum, ac faciendum omnem, et quam cun[que] d[ict]ae eius Matris, et fratris voluntatem tanquam de re ipsis cessa ad plenum, et cum omnibus alijs clausulis, et facultatibus in $\operatorname{sim}$ [ilibus] amplissimis cessionibus apponi solitis, consuetis, ac necessarijs, et ad arbitrium Sapientis extendendis vocans se tacitum, quietum, et satisfactum ab omnibus, et quibus cum[que] [?] sibi quomodocumq[ue] tam in bonis paternis, quam in fraternal Societate competentibus et competituris, et hanc cessionem et declarationem fecit atten[n[t]o] quod d[ic[t]us] Samuel se obligavit et obligat d[ic]tam eius Matrem nutrise, allere, bene tractare, ac mortuam tandem sepeliri facere et honorificentia, qua posibilitas ipsius Samuelis sibi permiserit, et atten[nto] quod a icta eius Matre habuit titulo donationis nonulla bona mobilia, et alia, renuncianis prepterea quatenus opus sit cuidem assignationi, favorem eius filiorum, ac si facta non esset; insuper, ad instantiam dicti Samuelis eius fratris declaravit se presentem cessionem facere citra ullum prenidicium debiti secum contracti ad quod teneri et obligatus esse voluit auxiliante sibi deo, si ad meliorem pervenerit fortunam et sic isti omnique alio meliori modo Ren[untiando]». 
Aunque la extensión de nuestros testamentos es desigual, guardan todos ellos relación con la importancia del legado testamentario en su doble vertiente espiritual y económica. A través de las mandas de carácter espiritual, asistencial y económico, podemos deducir el predominio de testadores que disfrutan de un nivel económico medio-alto. Esto, que en los testamentos de los católicos ragusinos se deduce de la fuerte inversión económica que realizan con la constitución de mandas de carácter espiritual (exequias, misas cantadas y rezadas, trentanarios, institución de beneficios y capellanías, institución de aniversarios, etc.), en el otorgado por los sefardíes locales se evidencia de manera más específica al establecerse una relación, en algunos casos exhaustiva, de los bienes que posee el testador, así como el destino que les quiere dar. De lo cual se deriva una clara diferencia entre los testamentos otorgados por los miembros de ambas comunidades que parece estar determinada por una distinta actitud ante el hecho de testar. Mientras el católico utiliza el testamento a modo de salvoconducto hacia la otra vida, intentando realizar un ultimo esfuerzo que le facilite su encuentro con Dios en las mejores condiciones, y, por tanto, preocupándole más el destino de su alma que el de sus bienes, el judío da a este tipo de documento un sentido más amplio que el simplemente espiritual. En el ámbito espiritual destaca el fenómeno que G. Nahon define en testadores sefardíes de Bayona como expresión de fervor religioso exteriorizado, devoción que atribuye a su ascendencia judeoconversa. Esta misma tendencia de piedad ardiente que caracteriza a la sociedad sefardí de Ragusa, concuerda con la que regía en la instituciones caritativas del entorno católico (¡y esto, justamente en una época de «reclusión» en el

65 DAD, Diversa de Foris, CXV, 50’-51: «Die 10 Febreij 1680. Samuel Filius supradicti Sig. Salomonis Lucena avedens in Cancellaria sponte recognavit supradicta subscriptionem esse Facta manu propria dicti Sig. Salomonis sui Patrij assensit qui registrari quandocumque, et in Fidem ego Georgis Gurglieni Publicus ac Iurato Ilustrissimo et extram reipublicam [?] subcripsi et quom similibus uter meosolito signo signari Lodis Dei. Die 4 Sept. 1680. Christophorus Vlaichi contrascriptus sponte ad interogationem controscripti Samuelis Luzena declaravit et declarat contrascriptum Iohanem Lucam Braici habuisse et integram solutionem controscriptarum litterari cambia praeter ducatos recepisse trigintaquinque de scudis 40 pro ducato quos Christophoros contentus et confesus est se habuisse et recepisse adicto Samuele pro integra pro reliqui solutione et satisfatione dictis litterariis cambia quem propria quietavit amplissima forma quas pecunias dictis Samuel et quietat in declaravit se solvisse de suis propriis pecunis animo rehabendi». 
gueto local!); también se asemeja a lo que ocurría en general en Italia tal como lo ha demostrado D. Malkiel en su erudito estudio sobre la influencia del medio cultural cristiano en testamentos judíos ${ }^{66}$. Una de estas expresiones se refleja en la preocupación por la confesión que tiene su paralelo en lo que sucedía en la sociedad católica ragusina ${ }^{67}$. Así, vemos como José Esperiel, al sentir que su salud se estaba deteriorando, manifestó su deseo de confesar sus pecados, encomendar su alma a Dios y hacer testamento ${ }^{68}$. Y Ester Maestro, antes de especificar sus mandas y legados nos dice que primeramente encomienda con toda humildad su alma a Dios, a quien le suplica se digne incluirla en el número de sus elegidos. Y puesto que no hay cosa más provechosa para los suyos que la bendición, suplica a Dios les otorgue la bendición que deben ellos siempre pedir y suplicar como se dice en la Sagrada Escritura ${ }^{69}$, deseándoles prosperidad en la vida y en el trabajo así como en su descendencia. A ellos se dirige con cariñosas y emotivas palabras, llena de paz y satisfacción en sus horas postreras, segura de que ha hecho el bien y que deja tras de sí hijos rectos y justos. Este mismo grado de espiritualidad se expresa en el testamento de Aarón Cohén en el que también muestra su gran amor por sus descendientes.

Otra de las mandas espirituales efectuadas por Aarón Cohén está relacionada con su obra Zecán Aharón, obra común como hemos visto de dos exegetas, él y su abuelo Salomón Ohev ${ }^{70}$ (Salamun Oef). Ninguno

${ }^{66}$ Véase D. Malkiel, «Jews and Wills in Renaissance Italy: A Case Study in the Jewish-Christian Cultural Encounter», Italia 12 (1996) págs. 7-69.

${ }_{67}$ Resulta importante señalar que las asociaciones caritativas judías de la época en Italia querían presentar la confesión como una expresión de enaltecimiento espiritual y moral y también como parte de las nuevas normas religiosas de la sociedad judía. Véase B. (Ardos) Rivlin, Mutual Responsibility in the Italian Guetto. Holy Societies 1516-1789 [en hebreo] (Jerusalem 1991) págs. 97-100

68 DAD, Testamenta Notariae, LVIII, 168': «e disse egli sentiva gravarsi dalla sua infirmità e che voleva confessare i suoi peccati a Dio, raccommandando l'anima sua a Iddio Benedetto e Lodato, e tistare per respetto della morte, e disse la confessione, e raccommando l'anima sua al Benedetto e Laudato Iddio, e tistò, e disse, che vuole...».

${ }^{69} \mathrm{Ibid}$ : «primieramente raccommando con ogni humilitá l'anima mia al signor Iddio, il quale prego, si degni ricevermi nel numero degli eletti suoi e perché non é cosa che piú profitta a figli quanto che la benedizione dopo di quella del signor Iddio delli loro genitori e si deve con instanza sempre da loro richiedere e domandare, come si ha in piú luoghi della sacra scrittura». 
de los dos comentó toda la Biblia y quizás no fuera ésa tampoco su intención. De los últimos Profetas falta Ezequiel; de los Profetas menores, Joel, Amós, Abdías, Jonás, Miqueas, Nahum, Sofonías y Ageo; y de los escritos históricos, Esdras y Nehemías. Aun así, supone un gran esfuerzo que prueba el dominio que los autores tenían de la literatura rabínica, $\mathrm{y}$, por encima de todo, prueba el arraigo de los judíos de Ragusa en la literatura rabínica y su capacidad de expresar en un lenguaje claro su devoción a las fuentes del judaísmo. Estas características se reflejan también en el testamento de Aarón Cohén, en su preocupación por la distribución de la obra y por hacerla llegar también a aquellos que no podían acceder a ella por motivos económicos. Todo ello otorgan gran valor a la labor espiritual que desempeñó, así como a la historia cultural de los judíos sefardíes de la costa este del Adriático.

\section{ApÉNDICE DOCUMENTAL}

Disposiciones testamentarias estipuladas por Nansí Benvenisti que, debiendo morir por razones obvias de justicia, hace este último testamento.

DAD, Diversa Notariae, XXVI/118, 114-115

\section{Die XVI Februarii 1571}

Mandato magnifici domini Reverendi signore Iunii Michaelis de Babalio eiusque minoris consilii infra erit registratum testamentum quondam Senior Benvenisti Nansi, haebrei, tenoris sequentis, videlicet.

70 Sus conocimientos halájicos fueron reconocidos por diversos estudiosos en sus Responsa. Entre ellos destaca R. Aarón ben Yosef Sassón, dirigente de las academias rabínicas de Salónica y de Constantinopla, que sancionó en el tribunal rabínico de Monastir el dictamen de Salomón Ohev que permitía el casamiento de ocho viudas ragusinas sin previo testimonio de enterramiento de los maridos desaparecidos como lo exige la halajá. Véase Responsa Torat Emet, Venecia 1626, n. ${ }^{\circ} 4$. Salomón 'Ohev mandó rezar por ellos en la sinagoga de Ragusa la oración por los difuntos. 
Die XVII Ianuarii 1571.

Io Senior Benvenisti Nansi dovendo morire per debito di giustitia faccio questo mio ultimo testamento, in prima lasso ducento ducati di oro, che siano maritate due pupille, secondo vorrá la mia madonna madre, delli miei beni, de meglio de miei beni, lasso alla Heura de Thalmud tora de Salonichio ducati cinquanta zec[c]hini. Item lasso al dottore di Ancona che è in Ancona dodeci scudi, lasso qui a Ragusi alla sinagoga de Hebrei per la mia sotterratione, scudi venticinque et cinquata lire di oglio per le mie esequie et le torce che andaranno honoratamente et al prete di Sinagoga cinque, lasso a David Galego per che mi ha servito scudi dodeci et oltra di questo che li sia pagato quello che dirà a che mi ha imprestato che puó essere sei scudi, sia pagato a mio servitore Josepho lo suo salario che mi ha servito, et di più dieci ducati. Item che sia pagato tutto quello che debbio dare in Venetia per mia debiti. Item anelli sei, et uno horologio quadro et uno medaglia d'argento indorata. Io ho dato a Salamon usque per impegnar, per riscattarsi dalle galee per scudi dodeci, che li debbiano dare scudi dodeci per riscattarli, et che torni la robba detta et darli finimento a venticinque scudi et debbiano dare delli beni miei alla madre di Abraham medico tre braccia et mezzo di panno venetiano, et sia dato alla moglie de Achar una pezza di mocaiaro de colori; lasso a Samuel Bono una catena d'oro de scudi quindici per sua moglie per servitii fattimi. Lasso che siano pagati de beni mei quello che si trovará che io sono debitore qui a Ragusi. Lasso ad Abraham de Isach Menachen cinquecento ducati per le fatturie et ministratione et servitii delle mie robbe et di più ducento scudi de zoe et la metá del mobile di casa et uno scritto che ho fatto a Abraham de Isach Menachen, che fu fatto in ferrara // ma dice in esso in Venetia che è de mille et ottocento et ottantacinque ducati et grossi non mi riccordo, de moneta venetiana a lire sei et soldi quattro per ducato che Io annullo qui in Ragusi dinanzi a Menachem Amariglio, Daniel Ludriga, Samuel Bono, Salamon usque. Voglio che si debba annullare, et cosí una ricevuta di gioie fatta finta, che é annullata d'inanti li sopra ditti testimoni, per che lo sopraditto scritto et la ditta ricevuta io ho fatto finta. Lasso a Josepho Salama cognato di Abraham medico dieci scudi per li servitii, che mi ha fatto et lo resto della mia robba et facultá lasso allo mio fratello, et lo faccio mio universale herede in fuora delli legati, che lasso et ancora che si debba dispartire cento cinquenta scudi infra Hierusalem et poveri huomini, che parerá a mio herede tutti li ve- 
stimenti mei alla levantina et soriana, che sono impegnati in Venetia si debbiano vendere et la valuta dare per elemosine a poveri, pagando lo riscatto di detta impegnatione. Uno scritto che ho fatto a Josepho Saralvo il giovane de trecento scudi é finto, che ha Abraham di Isach Menachen scritto allincontro, che faccia che sia annullato, et facendo questo lasso al detto Josepho la metá de mia vestimenti alla corta. Le robbe mie della Sinagoga et li testamenti vecchi che sono nella Sinagoga in Venetia li lasso in poter di mia madre, che li daga a che Sinagoga li piace. Prego Abraham di Isach Menachen, che faccia seppellire come si conviene a par mio con quelle solennitá, che conviene a un buono hebreo.

Io Paolo di Thadeo sono testimonio al presente testamento.

Io Biagio Vodopia cancelliere sono testimonio a quanto di sopra.

Hoc autem testamentum nullo testimonio rumpi possit.

Testamento de Moisés Calderón, hebreo levantino, encontrado en la notaría pública de Ragusa, donde fue registrado para su conservación, entre los testamentos de los vivos conforme a la costumbre de dicha ciudad.

DAD, Testamenta Notariae XLIII, 182-182'.

Testamentum Moyses Calderon, haebrei levantini.

MCD LXXII, indictione XV, die vero XXX Ianuarii Ragusii. Hoc est testamentum Moyses Chalderon, haebrei levantini, repertum in publica notaria eiusdem civitatis ubi datum fuerat ad servandum inter alia testamenta vivorum ex consuetudine civitatis cui testamento erant ad scripti testes signore Marinus Francesco de Tudisio, iudex, et Antonius Peregrinus, notarius, cuius tenor est huiusmodi, videlicet.

In Christi nomine Amen. Anno ab eiusdem Nativitate millessimo quingentesimo septuagesimo secundo, die XXIIII, Ianuarii Ragusii, in domo habitationis testatoris infraescripti, Io Moyse Chalderon, haebreo levantino, trovándomi infermo del corpo ma sano dell'intelletto, et di memoria per ogni caso che di me potesse avvenire et per ogni buon rispetto faccio 
et ordino questo mio ultimo testamento. Imprima ordino instituisco et faccio governatore et amministratore di tutti gli miei beni stabili et mobili presenti et futuri et existenti tanto qui a Ragugia et suo territorio quanto in qual si voglia parte del mondo Gecutiel Finzi, hebreo, con libera autoritá et piena potestà di riscuotere tutti gli miei crediti da qual si voglia persona comune Colleggio et Universitá tanto di quelli che al presente mi si spettassero quanto di quelli che per l'avvenire spettar mi potessero et pagare tutti gli miei debiti a tutti quelli che consteranno essere miei creditori et difendere tutte le mie ragioni in ogni giuditio innanzi qualunque giudice et giudici et di qualunque autoritá in ogni parte del mondo et fare et essercitare tutti gli atti della corte, che bisognassero per la recuperatione et conservatione de miei beni, ragioni et pertinenze che da poi la mia morte resteranno appartinenti alla haereditá da me lassata. Gli miei heredi di tutti gli miei beni faccio instituisco et voglio che siano gli miei figliuoli de beni miei dico tanto stabili quanto mobili, presenti et futuri, ragioni, usi, et pertinenze, che in cualunque modo, via, ragione, et causa mi competessero et competere mi potessero in ogni luogo del mondo epitropo et essecutore del presente mio testamento voglio, et prego, che sia il sopradetto Gecutiel Finzi, hebreo, al quale raccomando la essecutione di questo mio testamento quod nullo testimonio rumpi possit, et cetera.

Testamento de Isaías Cohén, hecho en Ragusa en casa del testador.

DAD, Testamenta Notariae, LI, 27'-28'

Testamentum doctoris Isayas Coenni, hebrei.

M. D. XCIX indictione XII die vero 17 maii Ragusii. Hoc est testamentum quondam doctoris Isayas Coenni, hebrei hodie sepulti repertum in notaria publica civitatis eiusdem ubi datum fuerat servandum inter alia testamenta viventium exconsuetudine cui testamento erant a scripti testes signore Stephanus Benessa, iudex, et Scipio Lucaris notarius cuius testamenti tenor sequitur.

Nel nome di Dio a di 6 di novembre 1597 in Ragugia in casa dell'ha- 
bitatione del infraescritto testatore Postanel ghetto ove habitano li hebrei. Trovandomi io Isai Coen dottore per la Dio gratia sano et sincero di mente nulla di meno indisposto del corpo, faccio et ordino questo mio ultimo testamento rievocando, cassando, et annullando ogni altro testamento et gionta di quello che per lo passato sin a questo giorno fatto havesti, per lo quale raccommando l'anima al Signor Iddio et il corpo voglio et ordino, che sia sepelito alle Ploće nel luogo ove si sepeliscono i miei fratelli hebrei, dichiaro di haver fatto di mia mano una nota di tutto il mio mobile sino a i 26 di ottobre passato, oltre del quale mobile debbo haver da i miei nepoti quattrocento ducati, de quali quattrocento ducati posso testare, però di detti quattrocento ducati ne lascio et dono ducento a detti miei nepoti, delli quali voglio che diano al mio fratello Cain de Jacob Coen ducati cinque per amore, et i rimanenti ducati, voglio che si riscótano da loro herede. Lascio alla nostra Sinagoga di hebrei ducati due ongari d'oro i quali ordino che siano dati al massaro prima che io sia sepelito. Lascio a donna Ora, figliola di donna Clara Abensachen in aiuto della sua dote cento ducati di talari sei per // ducato, e tutto il resto de miei beni tanto denari, quanto vestimenti et altre robbe lascio a donna Gioia già moglie del quondam Gioseppe, cirugico, et alle due figliole femine di detta Gioia, cioé Tamara et Rachel, le quali Gioia et sue figliole femine instituisco miei heredi universali, et ordino alla detta Gioia che debba maritar le sue figliole quando sará tempo di farlo in quei che le daranno i miei nepoti alla qual Gioia et sue figliole. Lascio il di sopradetto per li molti servitii et benefitii che ho havuto da lei in vita, et spero anche haverne in morte et dichiaro che ho prese certe sicurta delle quali consta in notaria, peró intravenendo qualche disastro, che Dio no voglia, commeto a Salamone Cabiglio, che le paghi de i denari che debbo haver da lui. Epitropi et commissarii miei faccio Isach Abuaf, et Moyse maestro pregándoli che per amor di Dio si préndano questo assunto, dando autoritá a detti comissarii come miei universali procuratori, che possanno riscuoter tutti i miei crediti, et di farne quel che di sopra ho detto, et per eseguirlo, cioé per riscuotere, voglio che póssano far quel tanto che io potrei fare se fussi vivo. Hoc autem testamentum.

Dichiaro che non volendo esser epitropo Moyse maestro, sia in luogo suo Abram Abeator, revoco il donativo di ducati cento, li quali lasciava a Donna Ora, figliola di donna Clara Abensachen, et che lo incontro uno scritto di cinquanta hongari d'oro li quali ho d'haver da Salamon Cabiglio 
sopra conti madieri da fabricar // nave, li quali madieri stanno in magazeno di detto Cabiglio. Dichiaro come il giorno di hoggi che sono nove di maggio deli 1599 ho d'havere da Salamone Cabiglio, come consta per un altro scritto di mano sua scudi cento novantasei a grossa. Dichiaro piú come ho d'havere da Aron Amadio talari trecento in circa sopra certi suoi pegni come ap[p]are per una nota della quale lui ha la copia di mano mia. Dichiaro come ho d'havere da maestro Marino Battitorre talari 63 Venetiani. Dichiaro come ho in casa salvo il vero ongari cinquantacinque in circa di modo che tutte queste robbe mie insieme con li ducati ducento che ho di havere dalli miei nepoti Xain de Isaii Coen e suoi cugini lasso alla detta Gioia et sue figliole, et tutti questi denari che io lascio tanto in contanti come in debiti si tenghino alla entrata in cambii come meglio parerá alli sopradetti epitropi, et l'usufrutto di quelli si dia alla detta Gioia et alle sue figliole per loro nutrimento, et non bastando se li dia di piu quello parerá a detti epitropi et questo sia at[t]ento que mariterá le sue figliole, essendo caso che morisse qualche una delle dette figliole due, cioé Tamara et Rachel prima che sian maritate che tutto resti all'altra. Ultimamente dico et dichiaro che cosí contanti, come pegni, come scrit[t]ure tutti siano in mano de Donna Gioia, la quale voglio che sia donna et patrona del tutto, che nessuno non le possa dimandar il conto ne cosa ventura, perché del tutto la faccio patrona assolutamente et voglio che questa mia volontá non si possa revocar in conto alcuno.

Testamento y codicilo de José Esperiel hecho de viva voz ante testigos; el testador, enfermo y postrado en su lecho, ruega a los testigos su registro oficial con el fin de que tanto el testamento como el codicilo adquieran validez a perpetuidad.

DAD, Testamenta Notariae, LV, 21-22

Testamentum nuncupativum Josephi Esperiel, hebrei, cum additione.

MDCXIV, indictione XI ${ }^{\mathrm{ma}}$, die vero XIII, mensi martii Ragusi. Hoc est testamentum [tachado:quod] nuncupativum quondam Josephi Esperiel, 
hebrei, presentatum Domino Consuli, signore Michaeli Marini de Bona et suis iudicibus honoribus, signore Ioanni Basilio et signore Aloysio Saraca cui testamento erant ascripti testes Haham Perachia Formon, Moyse de Sanson Habiglio, Rafael David de Abraham Lanciano, David Miranda, qui etiam testes fuerunt ascripti sub additione eiusdem testamenti presentata ut supra, tres ex quibus testibus Perachia Formon, David Miranda, et Raphael David de Abraham Lanciano personaliter constituti et separatim examinati coram dictis dominis David Coen super validitate dictorum testamenti et additionis deposuerunt iurati more hebreorum presentium testatorem tempore conditorum dictorum testamenti et additionis fuisse sanae mentis et intellectus illudque et illam fuisse suam ultimam voluntatem qua depositione testium audita dicti dominorum autenticaverunt dictum testamentum et additionem mandantes illud et illam huc describi pro eorum perpetua firmitate quorum testamenti et additionis tenor talis est, videlicet.

\section{Adi ultimo di febraro 1614}

Noi firmati qui basso entrammo a visitare il domino Josef Esperiel, che Dio guardi, e lo ritrovammo infermo giacendo sopra il suo letto, e lo domandammo, e respose sopra il si, si, e sopra il no, no, come gli huomini sani, che stanno quieti nel loro giuditio, e disse egli sentiva gravarsi dalla sua infirmità e che voleva confessare i suoi peccati a Dio, raccommandando l'anima sua a Iddio Benedetto e Lodato, e tistare per respetto della morte, e disse la confessione, e raccommando l' anima sua al Benedetto e Laudato Iddio, e tistò, e disse, che vuole che'l signore David Coen suo cognato, che Dio guardi, sia epitropo sopra tutte le sue // facoltà, e che veda tutti li libri de suoi conti, che tiene de dare ed havere, con qual si voglia huomo, e che faccia nelle sue facoltà o beni come gli aggradarà e gli parerà bene negli occhi suoi e raccommandò al detto suo cognato signore David Coen, che Dio guardi, che provegga sopra il suo figlio per incaminarlo nella strada conveniente e che lo accasi con la figlia de suo fratello David Esperiel bonae memoriae per che cosí é sua volontà. Questo é quello che havemo inteso di bocca del testatore predetto e per tanto havemo scritto tutto lo detto, e havemo firmato i mei nomi, acció che sia per tistimonianza e per prova della veritá e fu questo qui in Ragusa il di di Venere 19 del mese de Adar l'anno del 5374 dalla creatione del mondo, e tutto fermo.

Perachia Fermon, Moise de Sanson Habiglio, Rafael David de Abraham Lanciano, David Miranda. 
Tenor additionis. Adi 4 di Marzo 1614.

Item dopo di questo hoggi giorno di Marte di 23 del mese di Adar 5374 dalla creatione del mondo, noi altri firmati qui basso entrammo a visitare il detto Josef infermo della detta infermità col[lo]cato nel suo letto, et reposato in suo sentimento intieramente, et lo dimandammo, et lui rispose sopra il si, si e sopra il no, no, e tornò, e tistò per rispetto della morte, et affermò tutto lo detto di sopra, e disse di più che vuole che detto suo cognato David Coen non dia delle sue facultà o beni in poter di suo figlio fin che sia de vinti anni, et che fin che sia di vinti anni non sia detto suo figlio valioso, ne habbi potere nelle sue facoltà e beni ni niente salvo che stiano in potere del detto suo cognato epitropo conforme di sopra si è detto. Di più che vuole che detto suo figlio non si accasi fin che sia di vinti anni. Tutto questo habbiamo inteso de bocca del detto testarore e ci disse scrivete, et firmate tutto questo per testimonio e per prova // della verità, e per tanto havemo scritto, e firmato i nostri nomi per testimonianza e per prova della verità qui in Ragusa il di di Marte 23 del mese di Adar dell'anno 5374 della Creatione del mondo - tutto fermo Perachia Formon, Io Rafael David de Abraham Lanciano.

Testifichiamo noi qui sotto firmati come Josef Esperiel detto di sopra si partí da questo mondo il di di Giove 25 del mese di Adar 5374 dalla Creatione del mondo, e lasciò la vita, e morì dell'infirmità detta di sopra senza levarsi, ne migliorar della detta infirmità, e per prova della verità firmammo qui in Ragusa hoggi giorno di Marte primo del mese de Nisan 5374 dalla Creatione del mondo, e tutto fermo Perachia Formon, Moise de Sanson Habiglio, Rafael David Lanciano, David Miranda. Hoc autem testamentum et cetera. Additio nullo testimonio rumpi possit, quod quidem testamentum cum additione pro ut supra erat descriptum hebraicis caractere, et sermone, et interpretatum per Perachiam Formon Haham haebreorum Synagogae Ragusii sermone hispanico, et ex dicto sermone hispanico translatatum per signore Achillem Pozza, publicus et iuratus cancelarius Ragusii, ambos deputatos ad hoc per dictos dominos consules medio eorum iuramento respective. 
Ester, mujer de Moisés Maestro, para descargo de su conciencia y porque redundará en provecho de sus herederos, hace su último testamento disponiendo en conformidad con lo que le dicta su buena conciencia.

DAD, Testamenta Notariae, LVIII, 168-168'

Testamentum Hester, uxoris quondam Moysis, maestro.

MDCXXVIII Indictione XI ${ }^{\mathrm{a}}$, die vero XXIII, novembris Ragusii. Hoc est testamentum quondam Hester uxoris quondam Moysis, maestro, repertum in publica notaria ubi ex consuetudine civitatis inter alia viventium testamenta datum fuerat ad servandum modo vero pro dominis consolis extractum apertum lectum publicatum et ut infra admissum ad registrandum pro perpetua firmitate contentorum in eo cui testamentarum erant ascripti signore Hieronimus Menze, iudex, et signore Achilles Pozza, cancellarius, testis, tenoris sequentis, videlicet.

Nel nome del grande, et omnipotente signor Iddio Amen. Dentro del Ghetto degli hebrei in questa cittá di Ragugia nella casa della sólita habitatione dell'infrascritta testatrice, il dí 15 del mese di Novembre dell'anno 1628.

Io Hester moglie del quondam Moise maestro bone memoriae ritrovandomi aggravata dagli anni, in estrema mia vechiaia, et anche inferma di feb[b]re, pure tuttavia, mediante la gratia del signor Iddio, sana, e sincera di mente, e dell'intelletto e sapendo che non é cosa piú certa a noi altri che la morte ne piú incerta del dí, e dell'hora sua, et volendo io per discárico della mia conscienza, e perché cosí cognosco che sia per concernere a miei posteri fare il mio ultimo testamento e disporre secondo che mi detta la mia buona conscienza. Quindi é che detto e dispongo nel modo che segue cioé, primieramente raccommando con ogni humilitá l'anima mia al signor Iddio, il quale prego, si degni ricevermi nel numero degli eletti suoi e perché non é cosa che piú profitta a figli quanto che la benedizione dopo di quella del signor Iddio delli loro genitori e si deve con instanza sempre da loro richiedere e domandare, come si ha in piú luoghi della sacra scrittura, peró io dó la 
mia beneditione a tutti gli miei cari e diletti figlioli: David Salamone, Jacob, Josef, Samuel, Isach et Reiina et alle loro mogli, figli e figlie, et a quanti mai descenderanno da loro e da qualsivoglia di loro, si ché sempre mediante la gratia del signor Iddio, la quale sia di loro, in ogni futuro tempo prosperino di bene in meglio et multiplichino nel loro seme, nell'honore, nella robba, et in ogni e qualunque cosa la quale loro habbiano a profittare per aquistare la gloria e beatitudine eterna. Prego instantemente anzi ordino e lo mando a tutti li presenti miei figli e figlie che sotto quell' obligo che tieneno, in virtú della legge del Signore, verso loro genitori debbano farmi sepellire ac[c]anto del sepolcro del mio carissimo consorte quondam signor Moise Maestro, presento et quando levaranno le sue ossa per farle portare nella Terra Santa, secondo che mi hanno promesso che insieme con le sue portino anche le mie, et dichiaro che ho ordinato a Samuel, uno delli presenti miei figli che al presente si trova solo qui meco, dopo la mia morte, mi debba sotterrare sopra della terra cavando il mio corpo fuori della cassa nella quale sará portato mettendo sotto e sopra del detto mio corpo di calcina viva acció che prima siano spolpate le mia ossa, et cavarle poi come di sopra ho detto a suo tempo.

Dichiaro che Io in vita mia di quanto mai hebbi appresso di me ho dato et diviso ad ogniuno delli presenti miei figli la sua giusta portione tal che al presente non mi trovo havere di haver altro, nè in contanti, nè in ori ne in argenti, né in altra cosa, solo che una coppa, un bocale, et una tazza di argento tutto di peso di oncie novanta, et sono in pegno da persona che sa mio figlio Samuele, e per mano di detto mio figlio per talleri ottantacinque sono stati impegnati. Lasso per ragione di legato a Reijna presenta mia figlia che fu moglie di quondam Jacob Danon tutte quelle poche robicelle di mio uso che mi trovo havere in casa. //

Le quali ho ordinato al suddetto Samuele mio figlio a bocca che le mandi alla detta Reijna al quale Samuele, voglio, che si creda sopra di ció en ella loro quantità a quanto egli dirá dichiari che altra cosa nessuna non mi trovo havere, nè poco, nè assai, appresso di me nè meno in potere del detto Samuele mio figlio e per ció faccio a detto Samuele fine quiete fine finali et quietatione et generalmente con ordine espresso che da lui non si possa chiedere, nè domandare cosa alcuna, sia pro lode et gloria al signor Iddio. Amen. 
Aarón Cohén, hallándose postrado en cama y muy enfermo pero consciente, refunde y suscribe con su propia mano sus últimas voluntades para tranquilidad de su espíritu, antes de morir.

DAD, Testamenta Notariae, LXV, 164'-166

\section{Testamentum Aroni Isra Coen Haebrei}

Millesimo, indictione, mense ac die antescriptis, Ragusii. Hoc est testamentum quondam Aroni Isra Coen Haebrei, repertum in publica Notaria huius civitatis, ubi inter alia viventium testamenta datum fuerat ad servandum; modo vero per dominos consules extractum, apertum, lectum ac publicatum, et ut infra admissum ad registrandum pro sua perpetua firmitate; cui quidem testamenti erant ascripti dominus judex ser Vuladissavus Lucae de Goze, ac ego Florius de Staijs, coadiutor, testis, tenoris, qui sequitur, ut infra videlicet:

In Dei nomine amen. L'anno della sua salutifera Natività 1656, indictione nona, die vero nona mensis februarii, Ragusii domi solitae habitationis sitae in ghetto in Platea.

Io Aron Coen, anzi Aron Isra Coen, trovandomi giacente in letto gravemente ammalato, et non sapendo l'hora di mio transito da questa ad altra vita, et desiderando non morire senza ordinar per a punto le mie cose per la quiete dell'animo mio, però havendo io fatto in due fogli, che saranno qui inclusi in mio presente testamento tutta la mia ordinatione et ultima testamentaria volontà, al tenor di quali ordino et voglio che in tutto et per tutto si stia, attenda et osservi per essere mia ultima volontà, come dissi, et per essere sottoscritti di mia propria mano, et alli quali in tutto et per tutto mi riferisco, et non occorendomi dir altro, lode a Dio.

Segue il tenore di detti due fogli trovati inserti in detto testamento, scritti uno in spagnolo et l'altro in hebraico, et li quali da più persone, esaminate a parte, di dotti e periti hebrei, cioè Salamon Cagli et Abram Abeatar, precedente il loro giuramento more Haebreorum, sono stati tradotti in lingua italiana, per loro intiera intelligenza, et le dette tradutioni fatte da ciascuno di loro a parte, si sono trovate non discrepar in cosa al- 
cuna, ma concordar in tutto, et demandato di signori consoli si registrano qui di sotto.

Et segue tenor di primo foglio in carattere hebraico, videlicet:

Col nome di Dio. Iddio di Israel chiamai della mia angustia a Dio et mi risponde: In lui spera il mio cuoere. Et amatomi, mandi la sua medicina, et mi guarisca el suo servigio, per la sua pietà et misericordia, et perchè commanda alli miei figlioli et figliola dopo di me, et che guardi la strada di Dio per far limosina, et che stenda le sue mani, et che guardi gl'unici di anima mia, David et Aron, che Dio li guardi nella legge di Dio a suo servigio, a bona fine, che quella è la nostra vita et le longheze di nostri giorni. Et guardate et non vi scordate di Mishnaiod, che voi sapete alla mente. Et tu Aron, che stia forte nella Misna et Ghemara, et che ti affacendi un poco di giorno et un poco di notte con mio genero amato di anima mia, et con mio caro Raffaele Coen, ancora insieme con Manuele. Sarai con loro, che non sia nulla di continuo di leggere la elettione et affermar un tempo per la legge, che Dio sarà in aiuto vostro, et reparerà per voi, cosi sia, Amen. Alla mia figliola Ester gli lasso ducati cento per la sua heredità. Così ancora alla detta mia figliola il sefer piccolo con suoi adornamenti, con questo che non la possa dare se non per li suoi heredi dopo di lei, et che non la possa donar a nissuno, ne presentare, ne vendere, ne impegnare, et se lo volesse donare al suo figliolo Abram, li do licenza, ma con li patti detti di sopra. Gl'altri due sefarim siano per David et Aron con il medesimo patto di vendere, impegnare o presentare, con li suoi adornamenti. Sopra il resto di mia facoltà faccio curatore a mio genero Josef Baruf, et mio nipote Raffaele Coen, et ai miei nipoti David et Aron Franchi, che facciano quello che in questo li dichiaro. In primis: Facciano col nome di Dio stampare i libri di mio nonno, bona memoria, et el mio, che già è fatto et revisto. Et quello di mio nonno quando sarà copiato tutto, si vada facendo revisto per quel libro, et da poi si metta l'intitulatione, che ho fatto, et si faccia di tutto una dichiaratione sopra ogni perasa, metterli di sopra il libro di mio nonno, bona memoria, Semen Atov et letione Beresith, et sopra il mio Zecan Aron, et letione Beresith, et cosí sopra Neveim, et Chetuvim, et Maamari. A questo modo procurando, che la stampa sia chiara, et farà stampare 800, a mandare 200 in Constantinopoli, cento a Solonichi, cinquanta rispartiranno in Venetia, vinti in Soffia, dieci in Ancona, vinti in Roma, cinquanta in Terre Tudesche, cinquanta in li lochi di Anstradam, cento spartiranno in altri lochi per Italia et di Jerusalem, et qualche uno a 
chi dimandaranno. Et quelli di Jerusalem li daranno senza denari in ogni loco, secondo gli pare, et il resto che si vendano alla stima che costano. Il denaro che si cavarà, che si dia al signore Samuele Abuaf et suoi fratelli, et che li dispensi in mantenere loco di studio in Jerusalem in compagnia della sua parte, come li pare. Il resto della mia robba, che vederanno per li libri miei, et andaranno riscotendo et le teniranno in negotio per cinque anni facendo il negotio, quando si puó, stando al guadagno et lontano da la perdita. Et a fine di tempo, di guadagno che vi sarà, tiraranno la decima et daranno per l'aiuto di maritar orfane, dando ad ogni uno li parenti a trenta, dico ducati da banco fino, a quanto arrivarà detta decima. Et li parenti siano li nipoti di signora mia zia Streglia. Et se non bastano per questi, supliranno di guadagno, che se gli dia a 30 ducati, dico trenta, ad ogni una di loro. Seguitaranno la botega con Jacob detti cinque anni al modo che è stato fin adesso, et così andaranno seguitando. Et là sta il libro di bottega tutto notato et andaranno notando, dando debito di tutto in ducati quel che va, se in Venetia, et in Ancona, et in Turchia, et sopra quello che havesse di guadagno, le darano un $3^{\circ}$, et a bon conto di terzo che vada pigliando, come ha pigliato fin adesso. Et da poi, secondo che vedendo così farete, aiutatelo in quello che potrete. Et a sua madre che sta in casa et che stia, come sta per governo delli miei nipoti, il suo che gli dia, et che se gli dia per suo salario vinticinque ducati all'anno, con quello che gli si è dato et che se gli dia il resto la saia di broccato bianco. Il zupon di veluto di due colori, lo daranno alla mia sorella, che li dia a sue figlie, a chi le piace. Il resto di detto guadagno, cavando la decima, spartiranno in sei parti: una parte pigliarà Raffaele, et il resto, con denaro che restarà di capitale, tirando li lassiti detti di sopra et quelli che dirò qui di sotto, quello che restarà di capitale et guadagno et robba, li dono da adesso li due terzi per li miei nipoti David et Aron Franco, et un terzo a mio nipote, Abram Baruf et sue sorelle, et sia curatore di detti suo padre si no si maritaranno, et che li dia un terzo ad ogni uno di loro. Et quelli di miei nipoti, lo piglino loro, et che si sparta infra di loro la mità per l'uno. Et gli raccomando che tutti si governino con amore, et che non sia che per qualche discordia, Dio guarda, voglino disfar questo che qui dico. Et se qualche uno non volesse osservar, sia suo danno, che osservino gl'altri. Et quello che osservarà, sia benedetto. Havendo carico tutti i detti cinque anni, et da poi ancora sempre, David et Aron, et li vostri figlioli, dopo di voi di mandar per Talmudtora di Safet e Talmudtora di Jerusalem quello, che io mandava ogni anno per conto di mio signor padre et per me, quan- 
to, come sta nei libri, con ogni uno di loro. Et li medesimi mandarete voi David et Aron soli quel che io mandava ogni anno per conto di un hebreo Abram Molxo et per conto di un altro David Bensaxen, quali hanno lassato in mia mano di sua facoltà, come sta in libro. Et io per più sicurezza gli ho assignato in le case di Venetia, et perchè non habbia tanta fretta di mandar di più quel che è in libro, che cosí farete voi altri et li vostri figlioli dopo di voi di mandar quel che io mandava, come sta in detto libro per mio signor padre, come per li detti Molxo, et Bensaxen, et per me. Sia, sapete et vedendo che nelle case di Venetia ho speso gran denaro, le quali tengo la mia parte in quelli, et sia sempre obligato a quello, che havete di mandar per Erez Israel, rispartirete, come vedrete li libri et le note, che sia sempre obbligato a tutto, et quel che è più, sia il vostro. Là sono le scritture per valervi di loro per quello che ci fosse di bisogno, senza che nessuno possa pretendere per me cosa nessuna di loro. Et tutti li scritti di mio utile, siano come vani, et che non ci sia sostanza in loro.

\section{Aron Isra Coen}

Segue il tenore di altra scrittura o sia foglio scritto in spagnolo, videlicet:

Con il signor Paolo di Menze gli devo li cambi miei et della sicurtà, la nota sta in mio libro. Tengo in suo nome quello che sta in mano di Niccoló Bona, che ha dato al Magiair, et li rasi di Invitti et di Cachi. A signor David Oef se gli deve dare scudi cento, a conto di quali se gli è dati per mano di Raffaele scudi dieci. - Con Saralvo c'è scritto il conto in libro, et Manuel sa tutto, et delli conti che vi è in libro per dar luce à qualche cosa. Detto Manuele deve un scritto di ducati cento circa, quale li sia presentato, perchè ha copiato et copia i libri. A fuori di questo li pagará il suo salario di all'hora in qua, abbattendo quello che deve in libro fuori di questo scritto. Vedete di conciar i libri di Costura et tutto quello che farà di bisogno.

\section{Aron Isra Coen}

Hoc autem testamentum nullo testimonio rumpi possit etc. 


\section{RESUMEN}

A partir de testamentos que se conservan en el Archivo Histórico de Dubrovnik, este estudio intenta dar a conocer aspectos de la vida espiritual y de la actitud religiosa de los sefardíes de Ragusa en los siglos XVI y XVII. Se trata de testamentos judíos, otorgados ante notarios cristianos que luego los consignan en el registro local. Aunque su extensión es desigual, confirman todos ellos la importancia del legado testamentario en su doble vertiente espiritual y económica. Las mandas y legados de carácter moral, asistencial y crematístico dejan entrever el mundo socio-espiritual de los causantes, su nivel económico y sus prioridades espirituales así como la cohesión familiar y la relación con la Tierra de Israel, reflejando también la influencia del medio cultural católico circundante.

Palabras clave: Ragusa, Dubrovnik, testamentos, sefardíes.

\section{SUMMARY}

In this study, we will learn about the spiritual life and religious attitudes of the Sephardim of Ragusa, during the sixteenth and seventeenth centuries, by examining Jewish wills preserved in the Historical Archives of Dubrovnik. These wills were drafted by Christian notaries and later deposited in the local registry. While some of the wills are lengthy and others succinct, they all attest to the importance of these bequests in their dual role as spiritual and economic documents. The bequests and legacies, with their emphasis on donations to charitable causes and on bringing order to one's worldly possessions, reveal much about the donor's social-spiritual world, about his economic status and his spiritual priorities. We learn, for example, about the importance of preserving unison within the family and about the special connection to the Land of Israel. Reflected as well in these documents is the influence of the Catholic cultural milieu.

KeYwords: Ragusa, Dubrovnik, Wills, Sephardim. 